\title{
Geodetic point surface mass balances: a new approach to determine point surface mass balances on glaciers from remote sensing measurements
}

\author{
Christian Vincent $^{1}$, Diego Cusicanqui ${ }^{1,4}$, Bruno Jourdain ${ }^{1}$, Olivier Laarman ${ }^{1}$, Delphine Six ${ }^{1}$, Adrien Gilbert $^{1}$, \\ Andrea Walpersdorf ${ }^{2}$, Antoine Rabatel ${ }^{1}$, Luc Piard ${ }^{1}$, Florent Gimbert ${ }^{1}$, Olivier Gagliardini ${ }^{1}$, Vincent Peyaud ${ }^{1}$, \\ Laurent Arnaud ${ }^{1}$, Emmanuel Thibert ${ }^{3}$, Fanny Brun ${ }^{1}$, and Ugo Nanni ${ }^{1}$ \\ ${ }^{1}$ Université Grenoble Alpes, CNRS, IRD, Grenoble INP, IGE, 38000 Grenoble, France \\ ${ }^{2}$ Université Grenoble Alpes, CNRS, ISTerre, Grenoble, France \\ ${ }^{3}$ Université Grenoble Alpes, INRAE, UR ETGR, Grenoble, France \\ ${ }^{4}$ Université Savoie Mont Blanc, CNRS, Laboratoire EDyTEM, 73000 Chambery, France
}

Correspondence: Christian Vincent (christian.vincent@univ-grenoble-alpes.fr)

Received: 17 August 2020 - Discussion started: 11 September 2020

Revised: 15 December 2020 - Accepted: 14 January 2021 - Published: 10 March 2021

\begin{abstract}
Mass balance observations are very useful to assess climate change in different regions of the world. As opposed to glacier-wide mass balances which are influenced by the dynamic response of each glacier, point mass balances provide a direct climatic signal that depends on surface accumulation and ablation only. Unfortunately, major efforts are required to conduct in situ measurements on glaciers. Here, we propose a new approach that determines point surface mass balances from remote sensing observations. We call this balance the geodetic point surface mass balance. From observations and modelling performed on the Argentière and Mer de Glace glaciers over the last decade, we show that the vertical ice flow velocity changes are small in areas of low bedrock slope. Therefore, assuming constant vertical velocities in time for such areas and provided that the vertical velocities have been measured for at least 1 year in the past, our method can be used to reconstruct annual point surface mass balances from surface elevations and horizontal velocities alone. We demonstrate that the annual point surface mass balances can be reconstructed with an accuracy of about $0.3 \mathrm{~m}$ of water equivalent per year ( $\mathrm{m}$ w.e. $\mathrm{a}^{-1}$ ) using the vertical velocities observed over the previous years and data from unmanned aerial vehicle images. Given the recent improvements of satellite sensors, it should be possible to apply this method to high-spatial-resolution satellite images as well.
\end{abstract}

\section{Introduction}

Glacier surface mass balance observations are widely used to assess climate change in various climatic regimes because of their sensitivity to climate variables (e.g. Zemp et al., 2019; Marzeion et al., 2014; Kaser et al., 2006; Gardner et al., 2013; Huss and Hock, 2018; IPCC, 2019). In situ surface mass balance measurements have been conducted on only a few of the 200000 mountain glaciers worldwide (WGMS, 2017; Zemp et al., 2019). In the European Alps, about a dozen annual surface mass balance time series from in situ measurements extending over more than 50 years are available (WGMS, 2017). Recently, considerable efforts have been made to assess ice volume changes at the mountainrange scale over long time periods using geodetic measurements obtained from remote sensing techniques (e.g. Paul and Haeberli, 2008; Abermann et al., 2011; Gardelle et al., 2012; Gardner et al., 2013; Berthier et al., 2014; Brun et al., 2017). These geodetic methods determine glacier-wide volume changes, or glacier-wide mass balances, by differencing repeated determinations of glacier surface elevations obtained from airborne and spaceborne surveys usually over multi-year to decadal periods (e.g. Vincent, 2002; Bauder et al., 2007; Soruco et al., 2009; Berthier et al., 2014; Dussaillant et al., 2019). These methods are effective for estimating the overall glacier mass change and quantifying the related hydrological impacts or sea level contribution (e.g. Hock et 
al., 2005; Kaser et al., 2010; Huss, 2011; Immerzeel et al., 2013; Zemp et al., 2019). However, the meaningfulness of a climatic interpretation of these results is questionable. Indeed, glacier-wide mass balances are not solely driven by changes in climate but also by changes in glacier geometry controlled by the dynamic response of each glacier (Vincent, 2002; Fischer, 2010; Abermann et al., 2011; Huss et al., 2012; Vincent et al., 2017). Consequently, they do not provide a direct climatic signal. On the other hand, point surface mass balances provide a direct climatic signal which depends only on local ablation and accumulation (Huss and Bauder, 2009; Thibert et al., 2013; Vincent et al., 2004, 2017, 2018b). Ablation is related directly to the surface energy balance. Accumulation is related to precipitation but is also strongly influenced by valley topography. Indeed, glaciers are generally surrounded by very steep non-glacial slopes which capture precipitation over a larger area than that of the glacier itself. In this way, high accumulation values are due to downhill transportation and strong wind actions (Vincent, 2002). Statistical modelling enables us to extract a climatic signal from heterogeneous in situ observations of point mass balance networks independently of effects related to ice flow dynamics and glacier area changes (Vincent et al., 2018b). However, these previous studies showed that it is crucial to perform observations of annual point surface mass balance at the same locations every year. Unfortunately, the only way to presently obtain point mass balance data is to make in situ measurements. In particular, the net annual ablation in the ablation zone is usually obtained from ablation stakes. These point surface mass balance measurements require huge efforts involving field campaigns and the collection of data from stake measurements scattered over the glacier. This explains why so few in situ measurements are performed, especially on glaciers located in remote areas with very difficult access (e.g. Azam et al., 2018; Wagnon et al., 2013; Hoezle et al., 2017).

The objective of this paper is to propose an approach to determine point surface mass balances from measurements obtained by remote sensing techniques. In this way, we aim to determine point surface mass balances in ablation areas without setting up ablation stakes each year. We will develop this method using a comprehensive dataset of in situ measurements and analysis of ice motion, elevation changes and point surface mass balance data in the ablation area of the Argentière Glacier (French Alps). We will then validate our method in other areas of the ablation zone of this glacier and of the Mer de Glace glacier.

\section{Study area}

The Argentière Glacier is located in the Mont Blanc range, French Alps $\left(45^{\circ} 55^{\prime} \mathrm{N}, 6^{\circ} 57^{\prime} \mathrm{E}\right)$. Its surface area was about $10.9 \mathrm{~km}^{2}$ in 2018 (Fig. 1). The glacier extends from an altitude of about $3400 \mathrm{~m}$ a.s.l. (above sea level) at the upper bergschrund down to $1600 \mathrm{~m}$ a.s.l. at the snout. The length of this glacier is about $10 \mathrm{~km}$. It faces north-west except for a large part of the accumulation area (south-west facing tributaries). The annual surface mass balance ranges roughly from $2 \mathrm{~m}$ of water equivalent per year $\left(\mathrm{m}\right.$ w.e. $\left.\mathrm{a}^{-1}\right)$ in the accumulation area to about $-10 \mathrm{~m}$ w.e. $\mathrm{a}^{-1}$ close to the snout. This glacier is free of rock debris except for the lowermost part of the tongue below the ice fall located between 2000 and $2300 \mathrm{~m}$ a.s.l. In the region studied in detail at $2350 \mathrm{~m}$, the ice is generally free of debris. The debris cover can be 5 to $10 \mathrm{~cm}$ thick in some locations. The field observations of the Argentière Glacier (i.e. mass balance, thickness variations, ice-flow velocities and length fluctuations over 50 years) come from the French glacier monitoring programme called GLACIOCLIM (Les GLACIers, un Observatoire du CLIMat; https://glacioclim.osug.fr/, last access: 25 February 2021). For the present study, additional detailed observations were carried out in the framework of the SAUSSURE programme (Sliding of glAciers and sUbglacial water preSSURE; https://saussure.osug.fr, last access: 25 February 2021). The main part of our study focuses on a small area of the Argentière Glacier $\left(\sim 0.2 \mathrm{~km}^{2}\right)$ located between 2320 and $2400 \mathrm{~m}$ a.s.l. in the ablation zone (Figs. 1 and 2). In this area, the glacier is $\sim 600 \mathrm{~m}$ wide, the horizontal ice flow velocity is $\sim 55 \mathrm{~m} \mathrm{a}^{-1}$ (Vincent et al., 2009), and the maximum ice thickness is $250 \mathrm{~m}$ (Rabatel et al., 2018). Experiments conducted through boreholes (Hantz and Lliboutry, 1983) indicate that the bed is composed of hard rock with no thick or deforming sediment layer.

\section{Data}

In the selected area, annual point surface mass balances and ice flow velocities were monitored with a high positioning accuracy at the end of each ablation season between 2016 and 2019 from 19 ablation stakes (Fig. 2). Our study also used surface mass balance and ice flow velocity observations from a small part of the ablation zone of the Mer de Glace glacier at the location named "Tacul glacier" (Fig. 1).

The ablation stakes are $10 \mathrm{~m}$ long and made of five $2 \mathrm{~m}$ long sticks tied together with metallic chains. We performed the observations of annual point surface mass balance at the same locations every year. Errors in ablation measurements mainly come from the mechanical play of the jointed sticks. The uncertainties in the annual surface mass balance measurements performed in this ablation zone have been assessed at $\pm 0.14 \mathrm{~m}$ w.e. $\mathrm{a}^{-1}$ (Thibert et al., 2008). Topographic measurements were performed to obtain the 3D coordinates of the ablation stakes. For this purpose, we used a Leica 1200 Global Navigation Satellite System (GNSS) receiver, running with dual frequencies. Occupation times were typically $1 \mathrm{~min}$ with $1 \mathrm{~s}$ sampling, and the number of visible satellites (GPS and GLONASS) was more than seven. The distance between fixed and mobile receivers was less than 
$1 \mathrm{~km}$. The Differential Global Positioning System (DGPS) positions have an intrinsic accuracy of $\pm 0.01 \mathrm{~m}$. However, given the size of the holes drilled to insert the stakes, we estimate that the stake positions have an uncertainty of $\pm 0.05 \mathrm{~m}$.

Both velocity components are required. The vertical velocity is the vertical component of the surface velocity obtained from measuring altitude differences of the bottom tip of stakes. For this purpose, the emergence measurement is required to obtain the buried length of the stake. Thus, the purpose of emergence observations is two-fold. They enable us (i) to calculate the surface mass balance from two field campaigns and (ii) to obtain the altitude of the bottom tip of the stake using the altitude of the surface. In practice, the DGPS measurements are performed simultaneously with the emergence measurements in order to obtain the exact position of the bottom tip of the stake buried in ice. In this way, it is possible to monitor ice velocity along the three coordinate directions. Depending on the tilt of the ablation stakes, the size of the drilling hole and the mechanical play of the jointed stakes, we assume that the annual horizontal and vertical velocities are known with an uncertainty of $\pm 0.10 \mathrm{~m} \mathrm{a}^{-1}$.

Aerial photographs of the glacier surface were taken on 5 September 2018 and 13 September 2019 using the senseFly eBee X unmanned aerial vehicle (UAV). A total of 720 photos in 2018 and 673 photos in 2019 were collected with the on board senseFly S.O.D.A. camera (20 MP RGB sensor with a $28 \mathrm{~mm}$ focal length from an average altitude of $140 \mathrm{~m}$ above the glacier surface). Prior to the survey flights, we collected GNSS measurements of ground control points (GCPs) that consist of rectangular pieces of red fabric $(100 \times 60 \mathrm{~cm})$ with white painted circles $(40 \mathrm{~cm}$ diameter $)$ on the glacier (10 in 2018, 20 in 2019) and ten $40 \mathrm{~cm}$ diameter white circles painted on rocks on the sides of the glacier. The original horizontal resolutions of the orthophoto mosaics and digital elevation models (DEMs) are $10 \mathrm{~cm}$ and $1.00 \mathrm{~m}$, respectively. The photos from the survey were processed using the structure for motion (SfM) algorithm that is implemented in the Agisoft Metashape Professional version 1.5.2 software package (Agisoft, 2019). The SfM stereo technique was then used to generate a dense point cloud of the glacier surface. This dense point cloud was used to construct the DEMs using the GCPs surveyed during the field campaigns. A detailed description of the processing steps can be found in Kraaijenbrink et al. (2016) and Brun et al. (2016). The horizontal resolutions of the orthophoto mosaics and DEMs are $10 \mathrm{~cm}$ and $1.0 \mathrm{~m}$, respectively.

To calculate horizontal ice flow velocities over the studied area, we used the UAV orthophoto mosaics with COSICorr (Co-registration of Optically Sensed Images and Correlation), a software tool developed for image correlation (Leprince et al., 2007; Ayoub et al., 2009). Due to the velocities of the Argentière Glacier in this region $\left(\sim 55 \mathrm{~m} \mathrm{a}^{-1}\right)$, we resampled the UAV orthophotos at $1.0 \mathrm{~m}$ resolution because the correlation was too noisy even with very large window sizes (i.e. 512 pixels). The surface velocities were computed us-

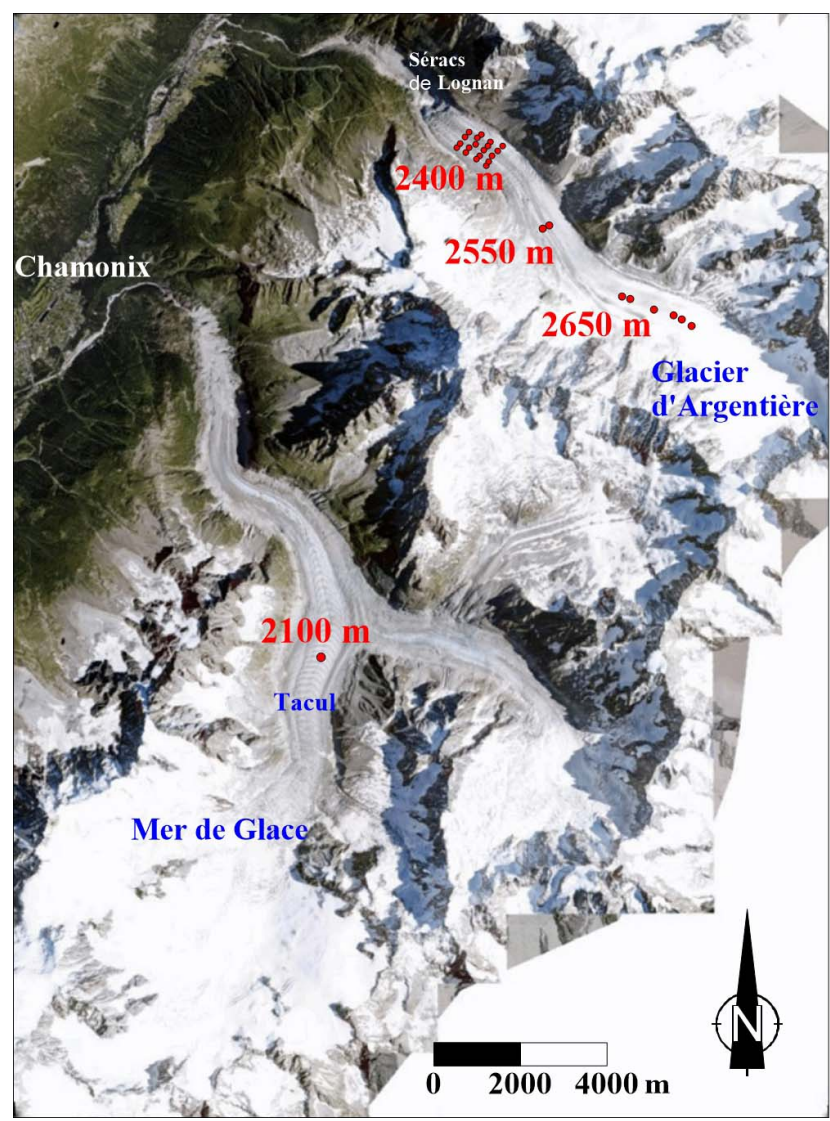

Figure 1. Map of the Argentière and Mer de Glace glaciers. The red dots on the Argentière Glacier are the ablation stakes used in this study for annual surface mass balance and ice flow velocity measurements in three regions of the glacier (at approximately 2400 , 2550 and $2700 \mathrm{~m}$ a.s.1.). Aerial photo from the French National Geographical Institute, 2015 (https://www.geoportail.gouv.fr/, last access: 25 February 2021).

ing an initial window size of 256 pixels, a final window size of 64 pixels and a step of 4 pixels. The output velocity field was filtered using signal-to-noise ratios (SNRs) provided by COSI-Corr. Using an SNR threshold greater than 0.9 provides a good compromise between output details, noise and computing time. A detailed description of the correct choice of the window size for correlation can be found in Kraaijenbrink et al. (2016).

To establish the possible errors in the correlation process, horizontal displacements on stable off-glacier areas were evaluated over 25 random points and provided a maximum horizontal error of $\sim 0.55 \mathrm{~m}$.

\section{Method}

We will now introduce the mathematical framework used further on. 


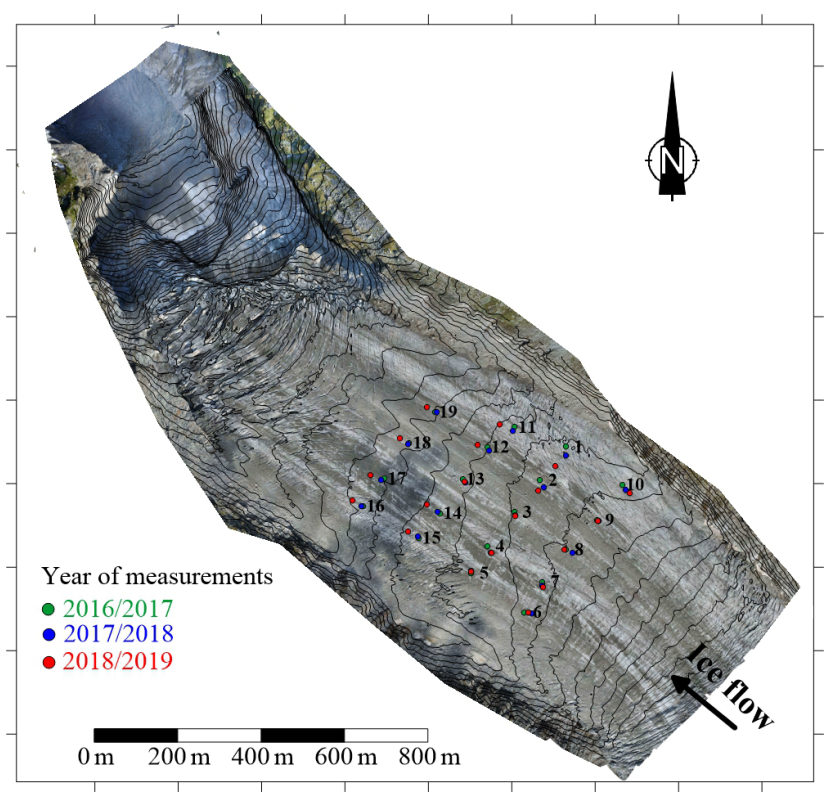

Figure 2. Map of the studied area in the ablation zone of the Argentière Glacier. The contour lines of surface topography correspond to the surface in 2018. The green, blue and red dots are the positions of the ablation stakes used for surface mass balance and ice flow velocity measurements when they were set up in 2016, 2017 and 2018, respectively. Aerial photo from unmanned aerial vehicle survey (5 September 2018).

\subsection{Emergence velocities}

The emergence velocity is the upward or downward flow of ice relative to the glacier surface. This flow compensates for the surface mass balance exactly if the glacier is under steady state conditions. The surface elevation change equation (Cuffey and Paterson, 2010, p. 332) expresses the surface mass balance as a function of surface velocity and surface gradient:

$b_{\mathrm{s}}=\partial S / \partial t-\left(w_{\mathrm{s}}-u_{\mathrm{s}} \partial S / \partial x-v_{\mathrm{s}} \partial S / \partial y\right)$,

with $b_{\mathrm{S}}$ the surface mass balance expressed in metres of ice, firn or snow $\left(\mathrm{m} \mathrm{a}^{-1}\right), S$ the surface elevation $(\mathrm{m}), u_{\mathrm{s}}, v_{\mathrm{s}}$ and $w_{\mathrm{s}}$ the components of ice flow velocity at the surface $\left(\mathrm{m} \mathrm{a}^{-1}\right)$, $\partial S / \partial x$ the surface gradient in the $x$ direction, and $\partial S / \partial y$ the surface gradient in the $y$ direction.

The term $w_{\mathrm{s}}-u_{\mathrm{s}} \partial S / \partial x-v_{\mathrm{s}} \partial S / \partial y$ is called the emergence velocity. If the horizontal $x$ axis is taken in the flow direction, $v_{\mathrm{s}}=0$, and the emergence velocity is written as

$v_{\mathrm{e}}=w_{\mathrm{s}}-u_{\mathrm{s}} \partial S / \partial x$.

Note that under steady state conditions, $\partial / \partial t=0$ and $b_{\mathrm{s}}=$ $-v_{\mathrm{e}}$. The emergence velocities can be calculated for each ablation stake from horizontal and vertical velocities and the slope of the surface $\partial S / \partial x$. In this way, we assume that the downslope direction is the flow direction. The slope of the

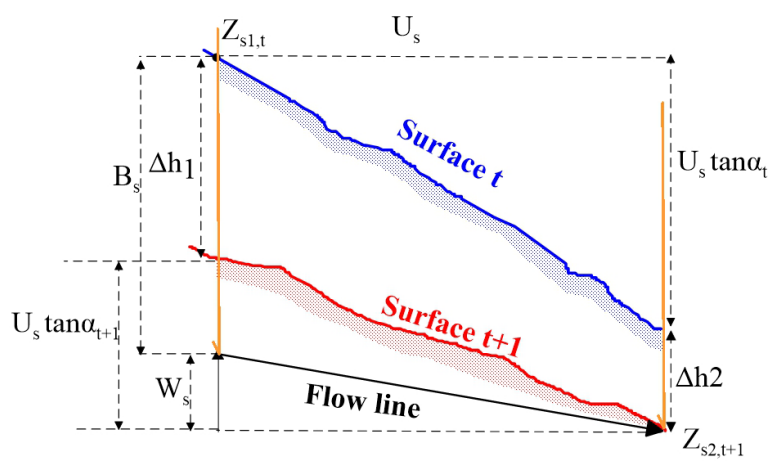

Figure 3. Diagram illustrating horizontal, vertical and emergence velocities $\left(\mathrm{m} \mathrm{a}^{-1}\right)$ observed from an ablation stake (orange). $U_{\mathrm{s}}$ $\left(\mathrm{m} \mathrm{a}^{-1}\right)$ and $W_{\mathrm{s}}\left(\mathrm{m} \mathrm{a}^{-1}\right)$ are the components of horizontal and vertical velocities, $\alpha_{t}$ and $\alpha_{t+1}$ are the slopes for the years $t$ and $t+1$, respectively, $Z_{\mathrm{s} 1, t}$ and $Z_{\mathrm{s} 2, t+1}$ are the elevations of the surface at each end of the ice flow vector, and $\Delta h_{1}$ and $\Delta h_{2}$ are the elevation changes $(\mathrm{m})$ at each end of the ice flow vector.

surface can be obtained from GNSS field measurements and calculated over a distance similar to that travelled by the stake over 1 year. In the ablation zone, the emergence velocities are positive, which corresponds to an upward flow of ice relative to the glacier surface. Note also that the vertical velocity can be positive or negative in any region of the glacier. The emergence velocity is a classical way to relate the surface mass balance to the thickness changes (Eq. 1). Unfortunately, as shown later in our study (Sect. 6.1), even if the horizontal and vertical velocities are accurately measured, the large uncertainties related to the slope and thickness changes prevent us from calculating the point surface mass balance from the emergence velocities.

At the yearly scale, according to Eq. (1) and Fig. 3 and considering that the $x$ axis is taken along the flow line direction (i.e. $v_{\mathrm{s}}=0$ ), the annual surface mass balance $B_{\mathrm{s}}$ between the years $t$ and $t+1$ is obtained from

$B_{\mathrm{S}}=\Delta h_{1}+U_{\mathrm{s}} \tan \alpha_{t+1}-W_{\mathrm{s}}=\Delta h_{2}+U_{\mathrm{s}} \tan \alpha_{t}-W_{\mathrm{s}}$,

where $u_{\mathrm{s}} \cdot \partial S / \partial x$ is replaced by $U_{\mathrm{s}} \tan \alpha_{t}$ or $U_{\mathrm{s}} \tan \alpha_{t+1}, U_{\mathrm{s}}$ is the annual surface horizontal velocity, and $\tan \alpha_{t}$ and $\tan$ $\alpha_{t+1}$ are the slopes for the years $t$ and $t+1$, respectively. $W_{\mathrm{s}}$ is the annual vertical velocity. $\partial S / \partial t$ is replaced by $\Delta h_{1}$ and $\Delta h_{2}$, which are the annual thickness changes observed at the ends of the annual ice flow vectors.

Figure 3 illustrates the components of Eq. (3).

Note that the slope of the surface may change from year $t$ to year $t+1$ and the expression depends on the selected slope and thickness changes $\Delta h_{1}$ or $\Delta h_{2}$ (Fig. 3). Obviously, the results are the same. 


\subsection{Calculation of the geodetic point surface mass balance}

Let us reconsider the emergence velocity formulation in order to express the point surface mass balance as a function of vertical velocity and altitude changes at the ends of the annual displacement vector.

According to Eq. (3) and given that $\Delta h_{1}+U_{\mathrm{s}} \tan \alpha_{t+1}=$ $\Delta h_{2}+U_{\mathrm{s}} \tan \alpha_{t}=Z_{\mathrm{s} 2, t+1}-Z_{\mathrm{s} 1, t}$ (Fig. 3), we can write the following:

$B_{\mathrm{s}}=Z_{\mathrm{s} 2, t+1}-Z_{\mathrm{s} 1, t}-W_{\mathrm{s}}$.

This expression has a great advantage in that it does not depend on the surface slope that can change from one year to the next. It is also independent of thickness changes that can change from one site to another.

The term geodetic point surface mass balance refers to the value of $B_{\mathrm{S}}$ obtained from Eq. (4). Once the vertical velocity is known, $B_{\mathrm{S}}$ can be obtained from topographical surface measurements alone. Note that even if the horizontal velocity is not included in Eq. (4), it is needed to estimate the positions at which $Z_{\mathrm{s} 2, t+1}$ and $Z_{\mathrm{s} 1, t}$ should be measured.

\section{Results}

\subsection{Annual horizontal and vertical velocities over the 3 years}

Annual horizontal and vertical velocities were measured from a network of 19 ablation stakes over 3 years between 2016 and 2019 (Fig. 2). The stakes were replaced each year and were always set up at the same locations using a handheld GPS device, allowing a relevant comparison, except for stakes 1 and 11 which were located in areas with large crevasses, preventing the possibility of drilling stakes at the chosen location. In addition, for the year 2018/2019, stake 12 was accidentally replaced at a distance of more than $30 \mathrm{~m}$ from its initial position due to both a lack of rigour and the uncertainty in the handheld GPS measurement. This difference in locations led to a difference in the horizontal velocity of $3 \mathrm{~m} \mathrm{a}^{-1}$ in a region with a strong horizontal gradient (left edge of the area in Fig. 4). However, it does not change the pattern of horizontal velocities or horizontal velocity changes with time. This is not the case for vertical velocities as described in the next paragraph. In the area of this network, the annual horizontal velocities range from 35 to $60 \mathrm{~m} \mathrm{a}^{-1}$. The annual ice flow velocities have been interpolated from kriging over the entire coloured areas shown in Fig. 4. In this way, we can accurately compare the ice flow velocities over 3 years, 2016/2017, 2017/2018 and 2018/2019, at the locations of each stake (Fig. 5a). Strong deceleration in horizontal ice flow velocities can be observed over these 3 years. On average, ice flow velocity decreased by 2.4 and $1.8 \mathrm{~m} \mathrm{a}^{-1}$ over the two periods 2016/2017-2017/2018 and
2017/2018-2018/2019, which corresponds to an average decrease of about $4.8 \%$ and $3.6 \%$ per year, respectively. Note that the regression lines shown in Fig. 5a are almost parallel, which means that the change in velocities is homogeneous in space.

The vertical velocities were obtained from the altitude changes in the bottom tip of the stakes from one year to the next (Fig. 3). In the studied area, the vertical velocities can be positive or negative and range from -4 to $4 \mathrm{ma}^{-1}$ (Fig. 4). The vertical velocities have been interpolated over the entire coloured areas shown in Fig. 4 using kriging. The patterns of vertical velocities are very similar for the years 2016/2017 and 2017/2018. We note some differences with the 2018/2019 pattern. As mentioned previously, stakes 1,11 and 12 set up in 2018/2019 are located at distances of more than $30 \mathrm{~m}$ from their initial positions. In addition, stakes 17,18 and 19 were replaced in 2018 at distances ranging between 25 and $30 \mathrm{~m}$ from their initial positions. These six stakes are shown with small dots in Fig. 5b. If we exclude the velocity values of 2018/2019 for these stakes, we can conclude that the measured vertical velocities are very similar over this 3 -year period. The differences do not exceed $0.5 \mathrm{~m} \mathrm{a}^{-1}$. The average of the differences is $0.01 \mathrm{~m} \mathrm{a}^{-1}$, and the standard deviation is $0.29 \mathrm{~m} \mathrm{a}^{-1}$. These differences barely exceed the measurement uncertainty. Note also that the vertical velocity changes could be affected by the horizontal motion changes or vertical strain rate changes as discussed in Sect. 6.

\subsection{Emergence velocities}

The emergence velocities have been calculated from Eq. (2) for each stake and reported in Fig. 6. The slope was determined from the digital elevation model using UAV measurements. We compared the emergence velocities obtained each year at each stake location (Fig. 7). Unlike the vertical velocities, the differences between emergence velocities calculated over the 3 years reveal a standard deviation of $0.8 \mathrm{~m}$ w.e. $\mathrm{a}^{-1}$. The value of emergence velocities is affected by large uncertainties related to the slope.

Combined with the measured thickness changes, the emergence velocity should make it possible to estimate the surface mass balance. However, our study shows that the uncertainties in the emergence velocity prevent us from calculating the point surface mass balance accurately. Indeed, the dispersion of $0.8 \mathrm{~m}$ w.e. $\mathrm{a}^{-1}$ is large compared to the spatial variability of about $1 \mathrm{mw}$ we. $\mathrm{a}^{-1}$ for point surface mass balance in the ablation zone of alpine glaciers (Vincent et al., 2018b).

For this reason, to calculate the surface mass balance, we suggest using the geodetic point surface mass balance described earlier rather than the emergence velocity. 


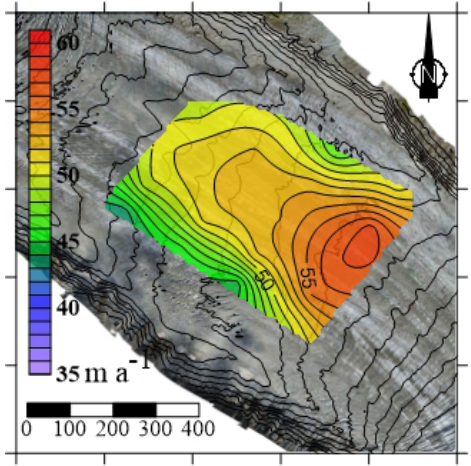

2016/2017

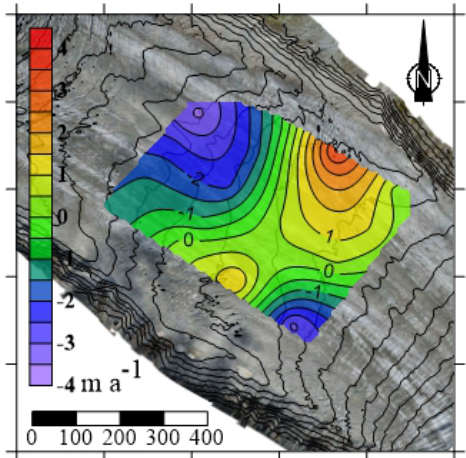

2016/2017

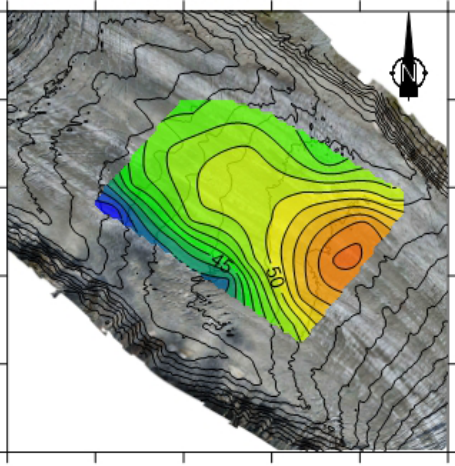

2017/2018

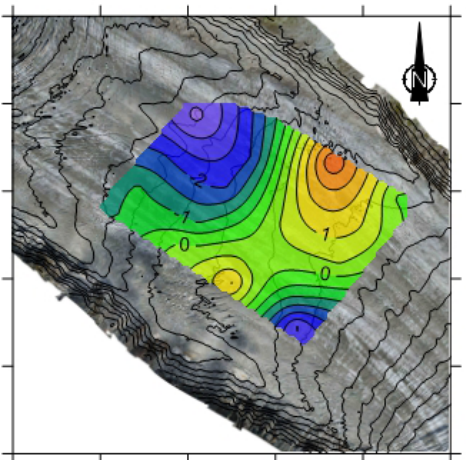

2017/2018

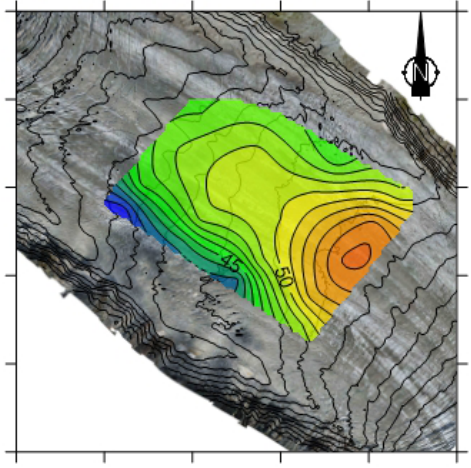

2018/2019

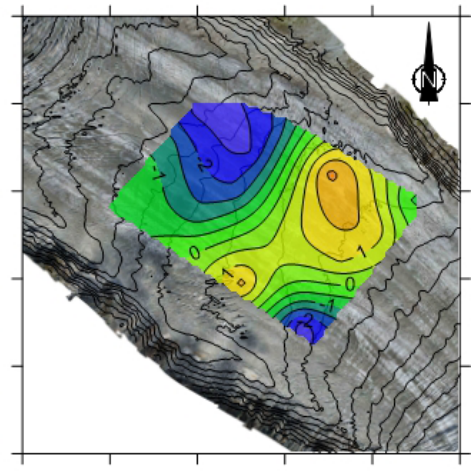

2018/2019

Figure 4. Horizontal (top panels) and vertical (bottom panels) ice flow velocities $\left(\mathrm{m} \mathrm{a}^{-1}\right)$ measured over 3 years from the ablation stakes. Note the different colour scales. Distances in metres.
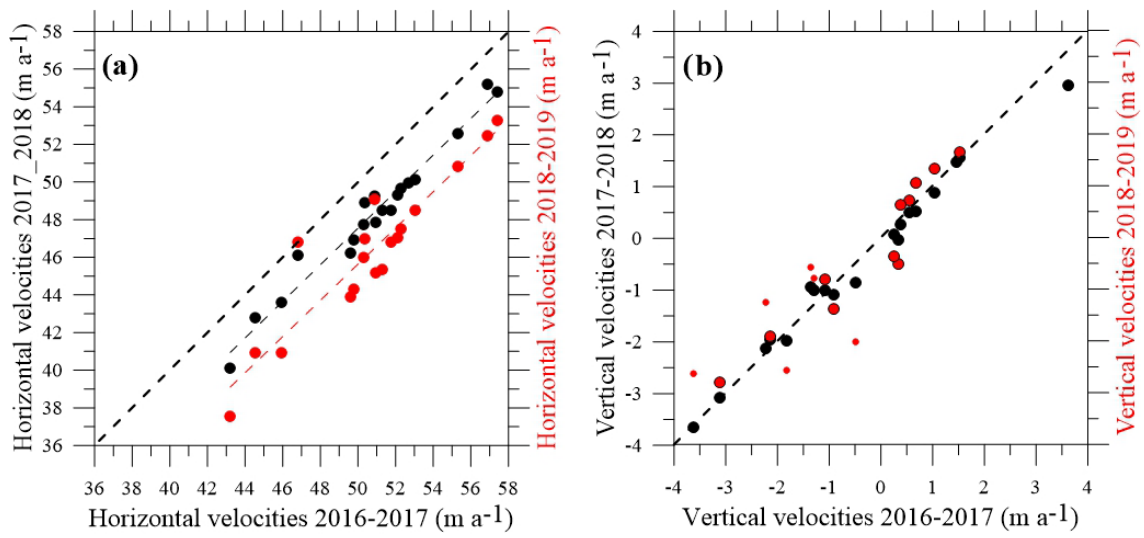

Figure 5. Comparison of horizontal ice flow velocities (a) and vertical velocities (b) between the years 2016/2017, 2017/2018 and 2018/2019. The black dots correspond to the comparison between the 2016/2017and 2017/2018 periods. The red dots correspond to the comparison between the 2016/2017 and 2018/2019 periods. The thick dashed line corresponds to the bisector and the thin dashed lines to the regression lines. The small dots in the figure on the right correspond to the stakes that were set up in 2018 at distances of more than $25 \mathrm{~m}$ from their initial positions.

\subsection{Geodetic point surface mass balances using in situ GNSS measurements}

The geodetic point surface mass balance is calculated according to Eq. (4). We first tested the method in the studied region of the Argentière Glacier at $2400 \mathrm{~m}$ a.s.l. using the in situ GNSS measurements. For this purpose, we used the altitudes of the surface at the stake locations for the years 2017 and 2018 and the vertical velocities observed in 2016/2017. The resulting point surface mass balances for the hydrological year 2017/2018 are compared with the observed surface mass balances and plotted in Fig. 8a. Note that the surface 

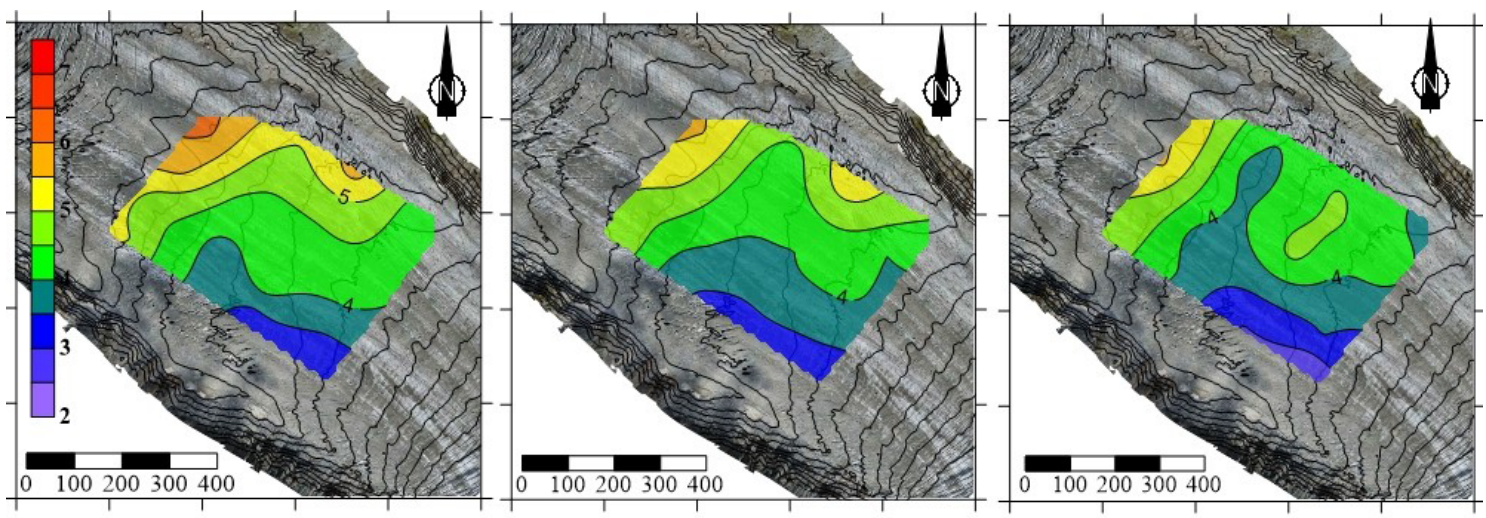

Figure 6. Emergence velocities between the years 2016/2017, 2017/2018 and 2018/2019 (m a $\left.{ }^{-1}\right)$.

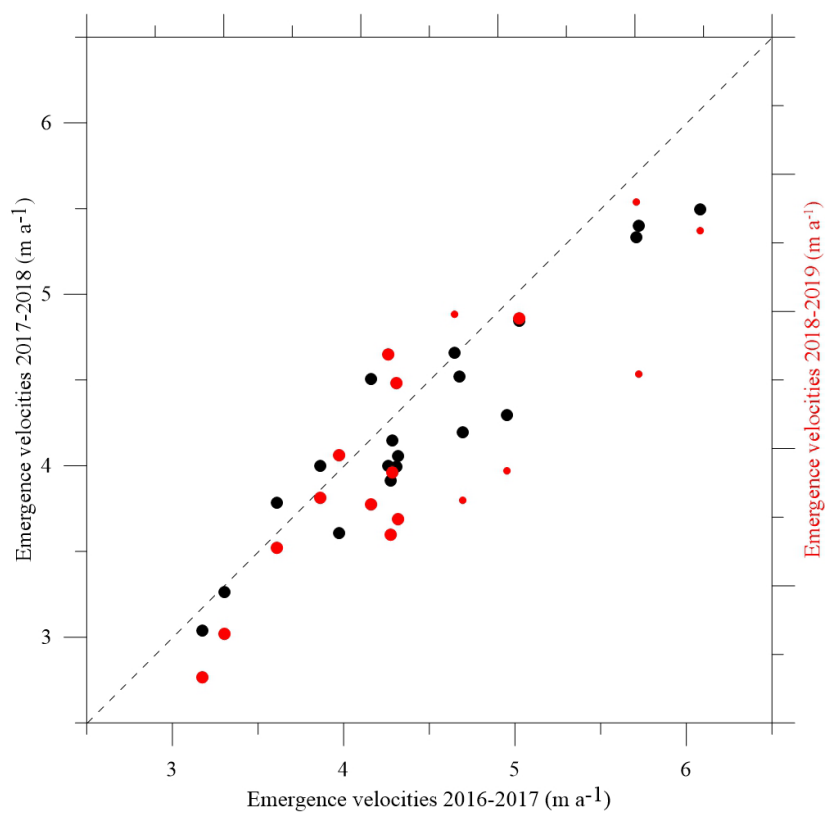

Figure 7. Comparison of emergence velocities between the years 2016/2017, 2017/2018 and 2018/2019. The black dots correspond to the comparison between the 2016/2017 and 2017/2018 periods. The red dots correspond to the comparison between the 2016/2017 and 2018/2019 periods. The red small dots correspond to the stakes that were set up in 2018 at distances of more than $25 \mathrm{~m}$ from their initial positions.

mass balances are in $\mathrm{m}$ of ice per year. The comparison shows very good agreement. The maximum difference is $0.39 \mathrm{~m}$ of ice per year and the standard deviation is $0.20 \mathrm{~m}$ of ice or $0.18 \mathrm{~m}$ w.e. per year. In addition, we calculated the surface mass balances of 2018/2019 from the vertical velocities observed in 2016/2017 and 2017/2018 (Fig. 8b). In this case, the comparison with the observed surface mass balances shows large discrepancies. However, a more detailed analysis reveals that the calculated and observed surface mass balances are very similar if the vertical velocities observed in
2016/2017 and 2017/2018 were measured exactly at the same location as the stakes measured in 2018/2019. In Fig. 8b, the large dots show the calculated and observed surface mass balances for the stakes located within a distance no greater than $15 \mathrm{~m}$. From this comparison, the differences are less than $0.5 \mathrm{~m} \mathrm{a}^{-1}$ of ice, and the standard deviation is $0.17 \mathrm{~m}$ of ice or $0.15 \mathrm{~m}$ w.e. $\mathrm{a}^{-1}$.

From this analysis, we conclude that the geodetic point surface mass balance can be obtained with an accuracy of about $0.2 \mathrm{~m}$ w.e. $\mathrm{a}^{-1}$ using the vertical velocities observed over the previous years. It requires the measurement of the horizontal ice flow velocity and the altitudes of the ends of the velocity vector exactly at the same location within a radius of less than $15 \mathrm{~m}$ compared to that of vertical velocity determination. In practice, the vertical velocities should be observed accurately between two years, $t$ and $t+1$, from stakes and GNSS measurements. Then, for the following or previous years, the point surface mass balance can be obtained from surface measurements only (without drillings and setting new stakes) using the horizontal velocity and the altitudes of the surface measured at each end of the horizontal vector. In the next section, we examine how such measurements obtained from remote sensing data can also be used effectively to determine the point surface mass balance.

\subsection{Geodetic point surface mass balances using remote sensing measurements}

Here, we used the same method described in the previous section. However, the in situ GNSS measurements used to determine the altitudes and horizontal velocities are replaced by remote sensing measurements. For this purpose, we used the horizontal velocities (Fig. 9) and the DEMs (Fig. 10) obtained from UAV surveys in 2018 and 2019. The vertical velocities are those observed in 2018/2019, 2017/2018 and $2016 / 2017$. The horizontal velocities have been neglected for stakes 9 and 10 given the poor quality of the correlation and the opening and/or closing of crevasses in the ice (close to 


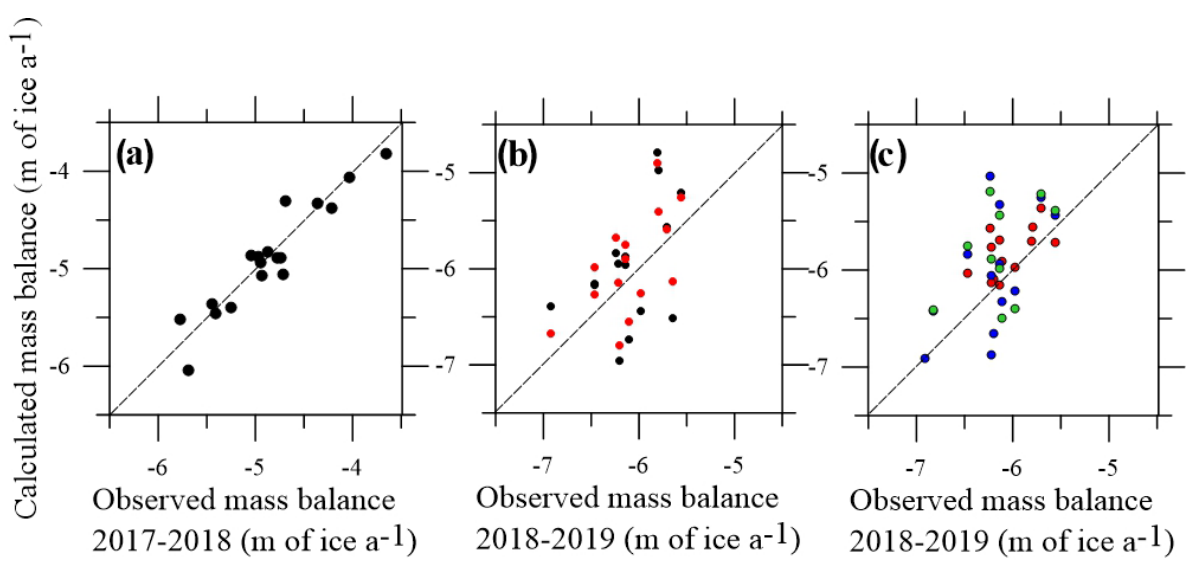

Figure 8. Observed and calculated point surface mass balances at $2350 \mathrm{~m}$ a.s.l. at Argentière Glacier. The point surface mass balances have been calculated (a) for the year 2017/2018 using the vertical velocities measured in 2016/2017 and elevations from GNSS measurements, (b) for the year 2018/2019 using the vertical velocities measured in 2016/2017 (black dots) and 2017/2018 (red dots) and elevations from GNSS measurements and (c) for the year 2018/2019 using elevations from remote sensing data (UAV data) and the vertical velocities measured in 2018/2019 (red dots), 2017/2018 (blue dots) and 2016/2017 (green dots). The large dots shown in Fig. 8b correspond to the stakes which were set up within a radius of less than $15 \mathrm{~m}$.

stake 10) that caused a drastic change between the photos, which subsequently affected the image correlation (Fig. 9).

Some details on the procedure are given below for the sake of clarity. The horizontal velocities retrieved from the UAV surveys were determined at positions where vertical velocities were measured. In this way, the coordinates $X Y$ of each vector end have been calculated (green dots in Fig. 9). Then we used the DEMs from 2018 and 2019 (Fig. 10) to determine the elevations of these points, $Z_{\mathrm{s} 1,2018}$ and $Z_{\mathrm{s} 2,2019}$ (see Eq. 4 and Fig. 3). The comparison between the in situ horizontal velocities and the velocities obtained from the UAV surveys reveals a standard deviation of $0.7 \mathrm{~m} \mathrm{a}^{-1}$.

The reconstructed point surface mass balances are compared with the observed surface mass balances in Fig. 8c. For this reconstruction, we used the vertical velocities observed in 2018/2019 (red dots), 2017/2018 (blue dots) and $2016 / 2017$ (green dots). For the reconstructions using the vertical velocities of 2016/2017 and 2017/2018, we excluded data from sites $1,11,12,17,18$ and 19 for which the stakes were measured at distances of more than $30 \mathrm{~m}$ from those of 2018/2019.

The differences between the observations and the reconstructed surface mass balances using the 2018/2019 vertical velocities are less than $0.45 \mathrm{~m}$ of ice per year, and the standard deviation is $0.24 \mathrm{~m}$ of ice or $0.22 \mathrm{~m}$ w.e. $\mathrm{a}^{-1}$. The differences between the observations and the reconstructed surface mass balances using the 2016/2017 and 2017/2018 vertical velocities show standard deviations of 0.42 and $0.40 \mathrm{~m}$ w.e. $\mathrm{a}^{-1}$, respectively.

From these results, we conclude that the point surface mass balances can be obtained with an accuracy of about $0.3 \mathrm{~m}$ w.e. $\mathrm{a}^{-1}$ using remote sensing measurements, assum- ing that the vertical velocities have been observed accurately over the previous years.

\subsection{Validation of the method: geodetic surface mass balances obtained in other regions}

In order to establish that the results are neither accidental nor site-dependent, we tested the method on other areas of the Argentière Glacier and on another glacier, which is the Mer de Glace located approximately $10 \mathrm{~km}$ away (Fig. 1) and for which vertical velocities were available. Here, we used GNSS in situ measurements given that accurate elevation observations from remote sensing data are not available.

First, we selected two ablation stakes in a sector of the Argentière Glacier located at $2530 \mathrm{~m}$ a.s.l. These stakes were replaced within a radius of $\pm 35 \mathrm{~m}$ each year between 2001 and 2018 (Fig. 1). Note that these measurements were not intended for vertical velocity determination but rather for point surface mass balance measurements. This explains why the stakes were not set up at exactly the same locations over the whole period. Note also that the region is not debris-covered and consequently the surface roughness is lower compared to the studied area at $2350 \mathrm{~m}$. Using Eq. (4) and the method described in the previous section, we calculated the point surface mass balances at these two stakes over the period 2001-2018. For this purpose, we used the average vertical velocities calculated over this period. In addition, the altitudes of each stake for each year of this period have been observed. These two stakes (named stake 2 and stake 3 ) are located about $120 \mathrm{~m}$ apart. The average calculated vertical velocities are $-0.24 \mathrm{~m} \mathrm{a}^{-1}\left( \pm 0.44 \mathrm{~m} \mathrm{a}^{-1}\right)$ and $-0.79 \mathrm{~m} \mathrm{a}^{-1}$ $\left( \pm 0.33 \mathrm{~m} \mathrm{a}^{-1}\right)$, respectively, and they did not show strong temporal changes (Fig. 11b). Note that the horizontal ve- 


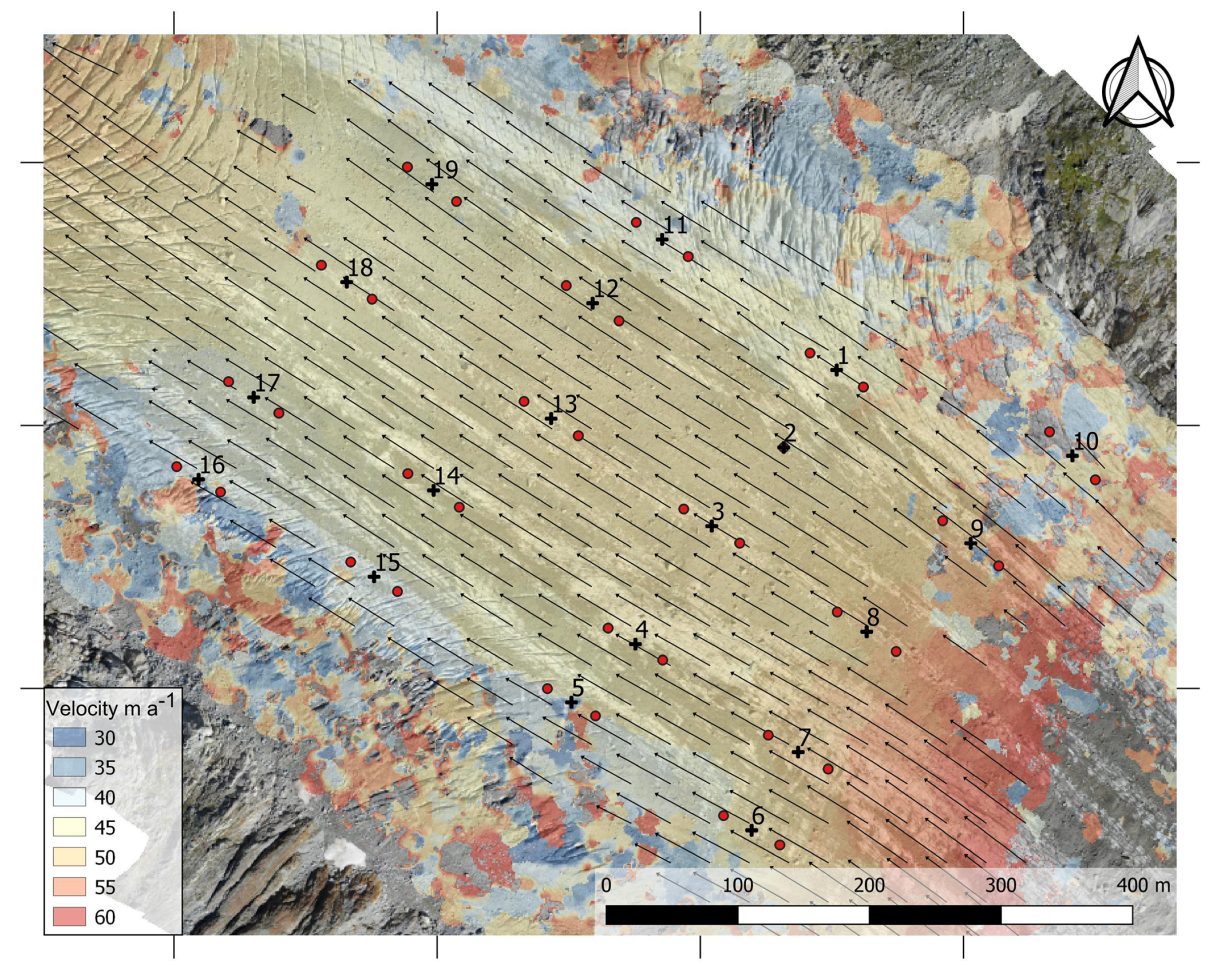

Figure 9. Horizontal velocities obtained from feature tracking (Cosi-Corr) using UAV images. The black crosses show the locations where the vertical velocities were observed. The red dots correspond to the ends of horizontal vectors for 2018/2019, determined from UAV images.

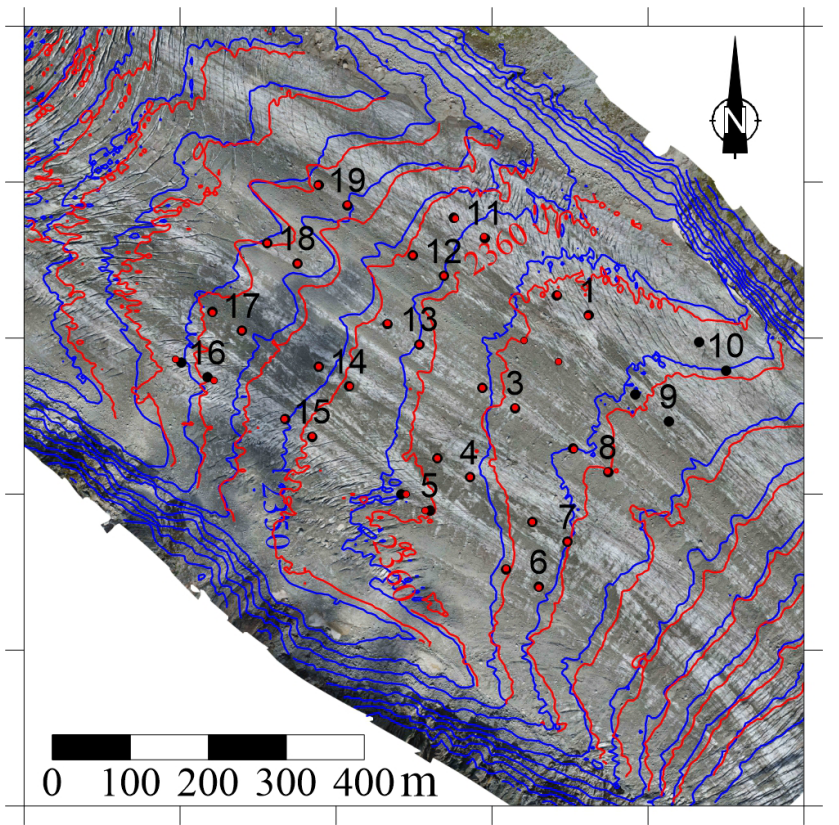

Figure 10. DEMs obtained from the UAV survey in 2018 (blue contour lines) and 2019 (red contour lines). The black dots correspond to the positions of the stakes in 2018 and 2019 observed from GNSS measurements. The red dots correspond to the ends of the horizontal velocity vectors obtained from UAV images. locity decreased from 75 to $50 \mathrm{~m} \mathrm{a}^{-1}$ in this region between 2002 and 2018 (Fig. 11a). The geodetic point surface mass balances are compared to the observations (Fig. 12a). The standard deviations of the calculated and observed surface mass balance differences are similar to those of the vertical velocities $\left(0.44\right.$ and $0.33 \mathrm{~m} \mathrm{a}^{-1}$, i.e. 0.4 and $0.3 \mathrm{~m}$ w.e. $\left.\mathrm{a}^{-1}\right)$.

Second, we tested the method in another sector of the Argentière Glacier close to the equilibrium line which is located close to $2800 \mathrm{~m}$ a.s.l. For this purpose, we selected six stakes (stakes 7, 8, 9, 10, 11 and 12) which were measured along a longitudinal section between 2650 and $2750 \mathrm{~m}$ a.s.l. (Fig. 1) over the period 2005-2018. In this region, the horizontal ice flow velocity is about $50 \mathrm{~m} \mathrm{a}^{-1}$ (Fig. 11a). Here again, the network of stakes was mainly designed for point surface mass balance measurements. Thus, given that the stakes were set $10 \mathrm{~m}$ deep in the ice and the surface mass balance ranges between -4 and $0 \mathrm{mw}$ we. $\mathrm{a}^{-1}$ depending on the year, the ablation stakes were not replaced each year. As the ablation stakes move with the ice flow, we selected only the measurements that were performed at the same locations. Indeed, after the first year following installation, the location of each stake was far from its initial position, and we cannot assume that the vertical velocity was similar. Consequently, 5 years are available to calculate the vertical velocities and to make the comparison between calculated and observed point surface mass balances (Fig. 12b). The standard deviations of 
calculated and observed point surface mass balance differences are $0.22 \mathrm{~m}$ of ice $\mathrm{a}^{-1}$, i.e. $0.20 \mathrm{~m}$ w.e. $\mathrm{a}^{-1}$.

Finally, we tested the method on another glacier, Mer de Glace (Fig. 1). On this glacier, we selected one stake at $2100 \mathrm{~m}$ a.s.l that was measured over 15 years between 2003 and 2018 (Vincent et al., 2018a). This ablation stake was set up each year at the same location within a radius of about $30 \mathrm{~m}$. Using the method described in the previous sections, we calculated the point surface mass balances at this stake over the period 2003-2018. The average calculated vertical velocity is $-1.10 \mathrm{~m} \mathrm{a}^{-1}$. Note that the horizontal velocity decreased from 80 to $50 \mathrm{~m} \mathrm{a}^{-1}$ and the thickness by $55 \mathrm{~m}$ in this region between 2003 and 2018 . The results are plotted in Fig. 12c. The standard deviation of the calculated and observed point surface mass balance differences is $0.40 \mathrm{~m}$ w.e. $\mathrm{a}^{-1}$.

\section{Discussions}

\subsection{Point surface mass balance obtained from emergence velocities vs. vertical velocities}

A classical approach to relate the point surface mass balance to thickness change is to use the emergence velocity (Cuffey and Paterson, 2010; Kääb and Funk, 1999). From this approach, the point surface mass balance is obtained from the sum of the emergence velocity and the thickness change (Eq. 1). However, the value of the mass balance reconstructed from the emergence velocity depends strongly on the selected surface slope and on thickness change, which both vary considerably with space and time. The value of the slope depends on the choice of the selected distance for the slope calculation and on the roughness of the surface.

In addition, the slope can change significantly from one year to the next. The emergence velocity is therefore not well-defined given that it depends strongly on the spatial and temporal changes in surface roughness, preventing an accurate determination of point surface mass balance, as shown in our study.

In contrast, in our analysis, we find that the changes in vertical velocity are insignificant over the 3 years of observations at $2350 \mathrm{~m}$. From the other long series of observations, one can also see that they are small over decadal timescales. Thus, we propose to reformulate the emergence velocity formulation (Eq. 1) in order to express the point surface mass balance as a function of vertical velocity and altitude changes at the ends of the annual displacement vector (Eq. 4). In this way, provided that the vertical velocity has been assessed from in situ measurements over previous years, the point surface mass balance can be determined from remote sensing measurements alone outside the period of field measurements with no need of prescribing surface slope or elevation changes as required when using emergence velocities, which introduces significant uncertainties. Our results from the de-

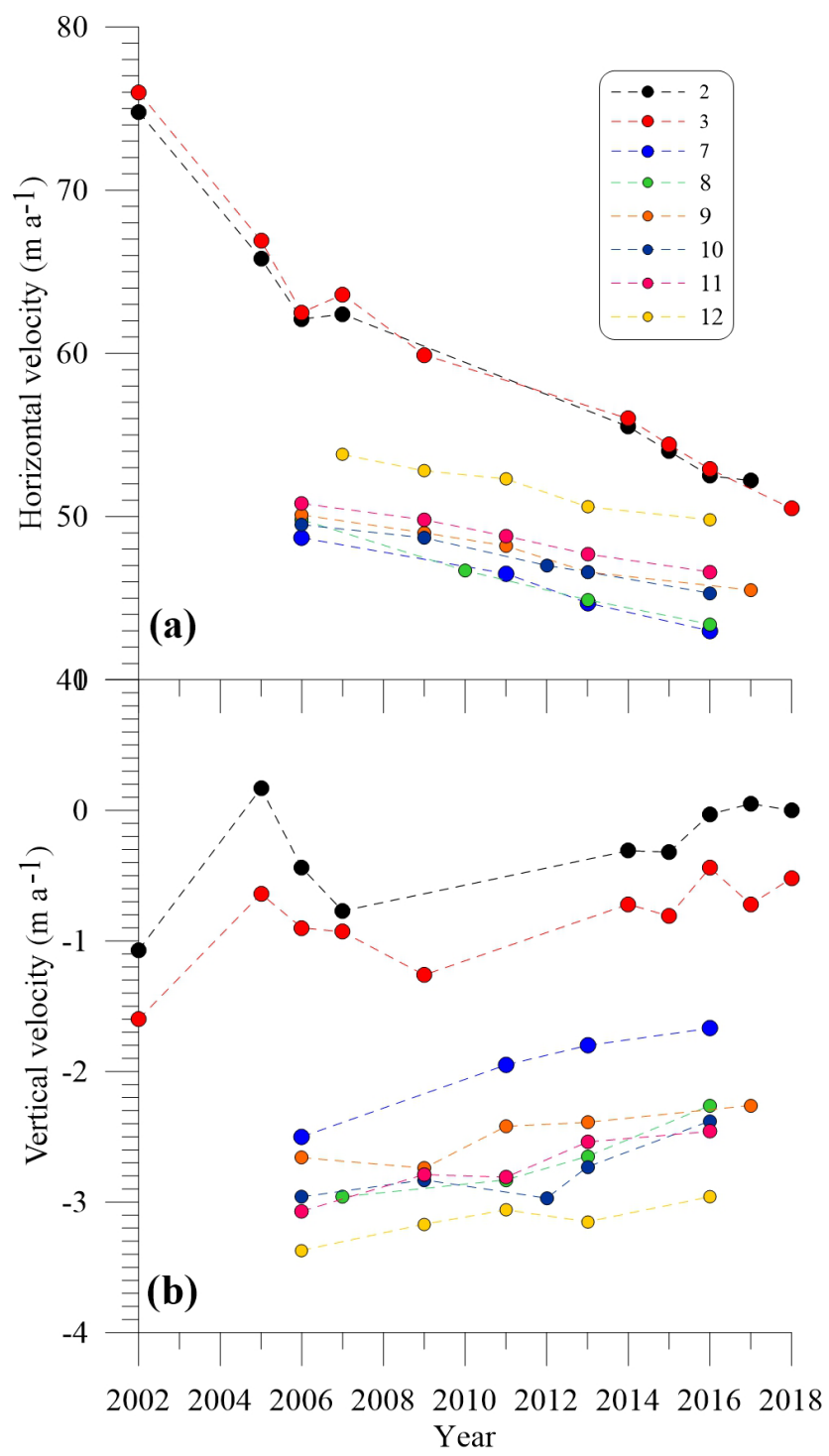

Figure 11. Horizontal (a) and vertical (b) velocities observed at the different stakes at $2550 \mathrm{~m}$ a.s.1. (stakes 2 and 3) and $2700 \mathrm{~m}$ a.s.1. (stakes 7, 8, 9, 10, 11 and 12).

tailed studied area at Argentière Glacier (2350 m a.s.l.), for which the observations were designed to accurately determine the vertical velocity, demonstrate that the surface mass balance can be obtained from this method with an accuracy of about $0.2 \mathrm{~m}$ w.e. $\mathrm{a}^{-1}$ from in situ GNSS measurements and about $0.3 \mathrm{~m}$ w.e. $\mathrm{a}^{-1}$ using elevations and horizontal velocities obtained from very high-resolution remote sensing data acquired from UAV surveys. 


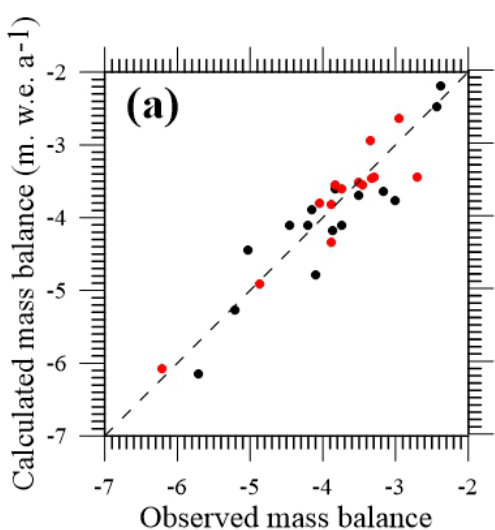

(m. w.e. $\mathrm{a}^{-1}$ )

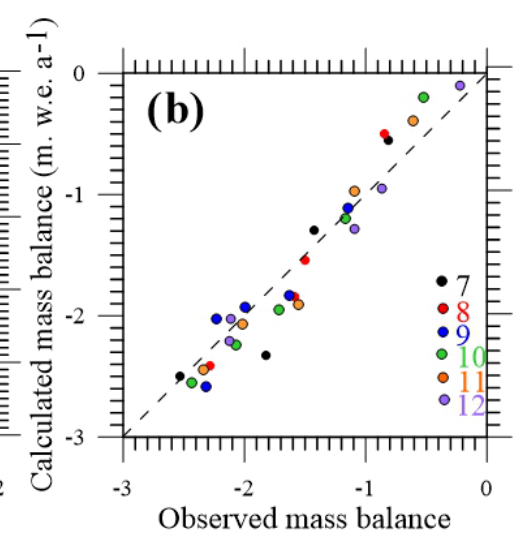

(m. w.e. $\mathrm{a}^{-1}$ )

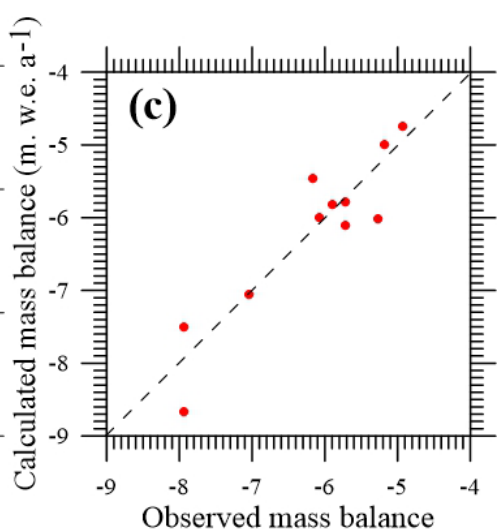

(m. w.e. $\left.\mathrm{a}^{-1}\right)$

Figure 12. Observed and calculated point surface mass balances from (a) two ablation stakes located at 2550 m a.s.1. at Argentière Glacier measured between 2002 and 2018, (b) six stakes located at around $2700 \mathrm{~m}$ a.s.l. at Argentière Glacier measured between 2006 and 2017 and (c) one stake located at $2100 \mathrm{~m}$ a.s.l. on Mer de Glace glacier measured between 2003 and 2018.

\subsection{Spatial and temporal variability in the vertical velocities}

\subsubsection{Analysis from observations}

Our dataset shows that vertical velocities strongly vary in space over the glacier surface. Our detailed observations from the network used between 2016 and 2018 at the Argentière Glacier $(2350 \mathrm{~m})$ showed that the vertical velocity change can exceed $0.3 \mathrm{~m} \mathrm{a}^{-1}$ if the stakes are located at distances of more than 25 or $30 \mathrm{~m}$ (Sect. 5.1). We showed that the surface mass balance can be reconstructed with an accuracy of about $0.2 \mathrm{~m}$ w.e. $\mathrm{a}^{-1}$ using the vertical velocities observed within a radius of less than $15 \mathrm{~m}$. Records from the whole network suggest that the vertical velocity spatial gradient can exceed $1.5 \mathrm{~m} \mathrm{a}^{-1}$ per $100 \mathrm{~m}$ in this region. As a consequence, a horizontal deviation of $10 \mathrm{~m}$ could lead to a vertical velocity change exceeding the measurement uncertainty $\left(0.15 \mathrm{~m} \mathrm{a}^{-1}\right)$. To better assess the vertical velocity spatial gradient over length scales of 20 to $100 \mathrm{~m}$, the vertical velocities have been calculated from 10 stakes set up in $2018 / 2019$ on a longitudinal profile located between stakes 3 and 13 (Fig. 2). Note that the distances between these stakes are small, and they enable us to assess the vertical velocity variations at small scales. According to measurements shown in Fig. A1, the spatial gradient can reach up to $0.02 \mathrm{a}^{-1}$, which is slightly more important than what we found previously $\left(0.015 \mathrm{a}^{-1}\right)$. We can conclude that reconstructing surface mass balance from remote sensing requires measurements of the horizontal ice flow velocity and the altitudes of the ends of the velocity vector exactly at the same locations, i.e. within a radius of less than $15 \mathrm{~m}$ compared to that of vertical velocity determination.

The analysis of temporal changes also deserves particular attention. The 3 years of detailed observations performed at $2350 \mathrm{~m}$ at Argentière Glacier does not reveal temporal changes exceeding the measurement uncertainties, as shown in Fig. 5b. Note that the longer series of observations available to study the temporal changes over decadal timescales were not designed to measure the vertical velocities. However, from the longer series of observations performed at Argentière Glacier at 2550 and $2700 \mathrm{~m}$ a.s.l. (Fig. 11b), we assessed a general temporal trend of about $0.07 \mathrm{~m} \mathrm{a}^{-2}$. We can conclude that the past period over which the vertical velocities are determined should not exceed 4 years in order to not exceed an uncertainty of $0.3 \mathrm{~m}$ w.e. $\mathrm{a}^{-1}$ on the reconstructed surface mass balance. This conclusion could be different with stronger temporal changes in vertical velocities. Further observations and analysis are needed to better estimate the temporal changes.

\subsubsection{Analysis from numerical modelling}

To analyse the spatial and temporal variabilities in the vertical velocities over the entire glacier, we performed 3D fullStokes ice-flow simulations for two different glacier geometries using a surface DEM measured in 1998 and 2015 and reconstructed bedrock topography (Rabatel et al., 2018). The calculation is solved using the Elmer/Ice model (Gagliardini et al., 2013). The linear basal friction parameter is inferred from surface velocity and topography measurements made in 2003 (Berthier et al., 2005) using the adjoint-based inverse method (Gillet-Chaulet et al., 2012). For each given glacier geometry, we compute the corresponding flow solution and assume constant friction over time. Therefore, changes in velocity are only induced by changes in the glacier geometry between 1998 and 2015. We used an unstructured mesh with a $100 \mathrm{~m}$ horizontal resolution refined down to $10 \mathrm{~m}$ in the stake network monitoring area at $2400 \mathrm{~m}$ a.s.l.

By integrating the mass conservation equation for an incompressible fluid along the vertical axis, we can write the following: 
$w_{\mathrm{s}}=w_{\mathrm{b}}-\int_{z_{\mathrm{b}}}^{z_{\mathrm{s}}} \frac{\partial u}{\partial x}+\frac{\partial v}{\partial y} \mathrm{~d} z$

where $w_{\mathrm{b}}$ is the vertical velocity at the bed, $z_{\mathrm{s}}$ is the surface elevation, and $z_{\mathrm{b}}$ is the bed elevation. Vertical velocity at the surface can therefore be viewed as a sum of a component coming from sliding along the bedrock and a component coming from convergence/divergence of the ice flow integrated over the glacier thickness. For example, local depression in the bedrock topography creates negative vertical velocity $w_{\mathrm{b}}$ at the glacier base but also flow convergence that creates positive vertical velocity resulting in a smoothing of surface vertical velocity $w_{\mathrm{s}}$ by the ice deformation. Figure 13a shows the modelled vertical surface velocity in 2015. At the scale of the glacier, vertical surface velocities are spatially heterogeneous due to a combination of bedrock slope and the ice flux divergence/convergence (Fig. 13a). In the model, the basal vertical velocity $w_{\mathrm{b}}$ produced by ice flow along the bedrock can lead to small-scale variability in the basal vertical velocity that can be visible at the surface when sliding velocity is significant, as modelled around $2400 \mathrm{~m}$ a.s.l. in the studied stake network (Fig. 13a). Bedrock topography is therefore likely the origin of the observed pattern at $2400 \mathrm{~m}$ a.s.l. (Fig. 4). The pattern differences between the observations and the modelling results are likely due to bedrock elevation errors. Although the pattern of horizontal velocities is reproduced well (Fig. 13b), it seems difficult to properly reconstruct the vertical velocities.

Our numerical experiments were used to analyse the temporal changes in vertical velocities. We found that the response of the vertical velocities at the glacier surface to changes in glacier thickness over time is sensitive to the bedrock slope (averaged over a distance greater than the ice thickness). Consequently, a decreasing vertical velocity magnitude should be associated with decreasing horizontal velocities when bed slopes are significant (Fig. 14). However, the magnitude of small-scale (length-scale inferior to glacier thickness) spatial variations in vertical velocity due to bedrock topography seems to be little affected by the large change in horizontal velocities (Figs. 14 and 15). We show that reduced amplitude of $w_{\mathrm{b}}$ due to decreasing sliding speed is compensated for by the reduced amplitude of the ice flux convergence/divergence produced by bedrock anomalies (red arrows in Fig. 15). Bedrock depressions and bumps of sizes comparable to the glacier thickness produce, respectively, convergence and divergence in the ice flow, creating vertical velocities of opposite signs compared to the velocities created by sliding at the glacier base. These two components of the surface vertical velocity decrease in magnitude in response to thickness changes resulting in a limited change in the sum of the two components and therefore in surface vertical velocities. This results in nearly constant vertical velocity in which large-scale averaged bedrock slope is low, which explains why the observed pattern of surface vertical velocity (Fig. 4) is conserved well over time.

In summary, at large scales, the magnitude of surface vertical changes over time are proportional to bedrock slope and changes in horizontal velocities, while at small scales, the spatial patterns tend to be conserved over time due to compensation between changes in bedrock vertical velocities and ice flux convergence/divergence. These findings suggest that our method is likely applicable only in areas of low bedrock slope.

Note that, in our study, we used the annual velocities measured at the end of the ablation season (from September to September) such that potential seasonal changes in the vertical and horizontal motion or in basal uplift and bed separation (e.g. Sugiyama et al., 2004; Nienow et al., 2005) are not expected to bias the geodetic annual surface mass balances obtained from the vertical velocities.

\subsection{Uncertainties in geodetic point surface mass balances}

The uncertainty related to the point surface mass balance determination results from uncertainties in the elevation measurements and in the vertical velocity. Using Eq. (4) and assuming the independence of the different sources of uncertainties, the overall uncertainty related to the reconstructed point surface mass balance is obtained by applying the method of error propagation and assuming uncorrelated errors:

$\sigma_{\mathrm{b}}^{2}=2 \sigma_{z}^{2}+\sigma_{w}^{2}$,

in which $\sigma_{\mathrm{b}}, \sigma_{z}$ and $\sigma_{w}$ are the uncertainties relative to the point surface mass balance, elevation and vertical velocity, respectively.

The uncertainty in elevation depends both on the method of $X Y$ positioning, the surface slope or roughness, and the method of altitude determination. Depending on the surface roughness, we can assess the elevations with an accuracy ranging from 0.1 to $0.3 \mathrm{~m}$ from UAV measurements, as shown in this study.

The uncertainty in vertical velocity is $\pm 0.1 \mathrm{~m} \mathrm{a}^{-1}$, as mentioned in the Data section. However, additional uncertainty could come from the method of elevation observations for the bottom of the stakes. Indeed, the GNSS measurements are commonly related to the surface of the ice at the location of the stakes and not to the summit of the stakes. Consequently, the altitude of the bottom of each stake results from the difference between the altitude of the surface and the buried height of the ablation stake. Indeed, this determination is accurate only if the measurement of emergence has been performed exactly from the point on which the GNSS measurement was made. Unfortunately, in most cases, one operator held the stick of the GPS antenna at the ice surface close to the ablation stake, and another operator measured the emergence of the stake but not exactly from the surface alti- 

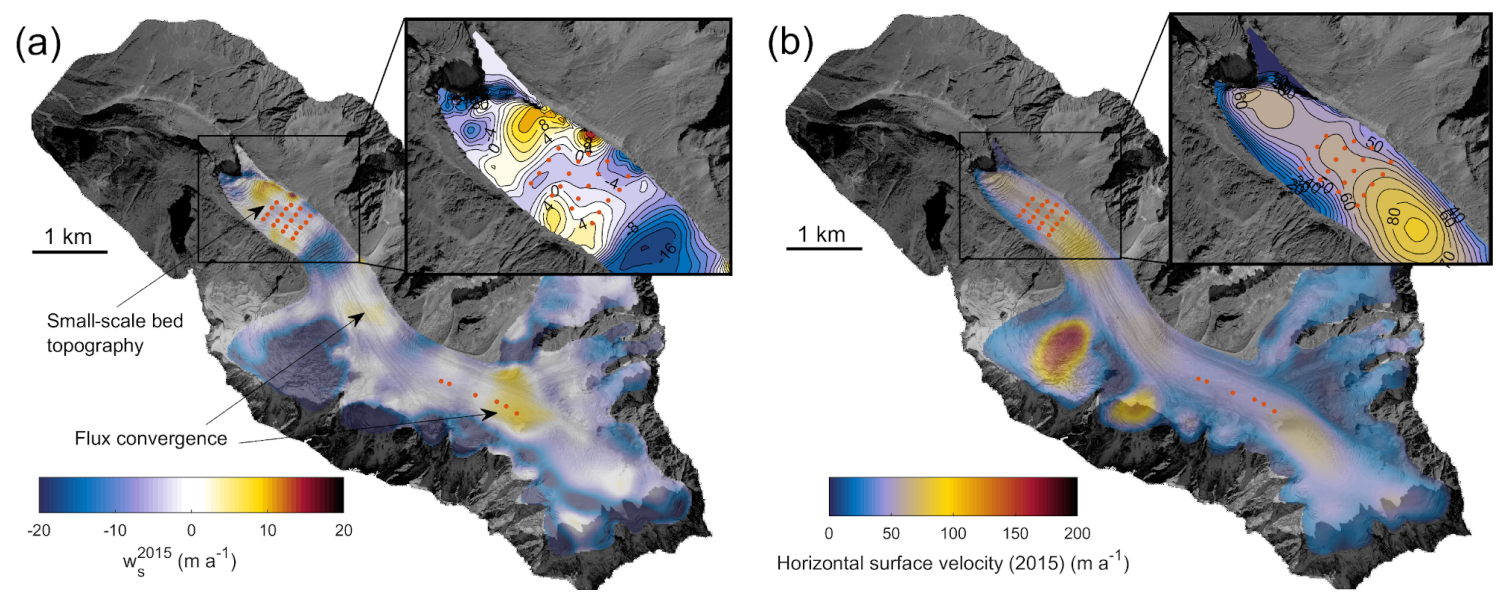

Figure 13. Vertical (a) and horizontal (b) surface velocities modelled at Argentière Glacier in 2015. Red dots show the locations of the ablation stakes set up at 2400 and $2650 \mathrm{~m}$ a.s.l.
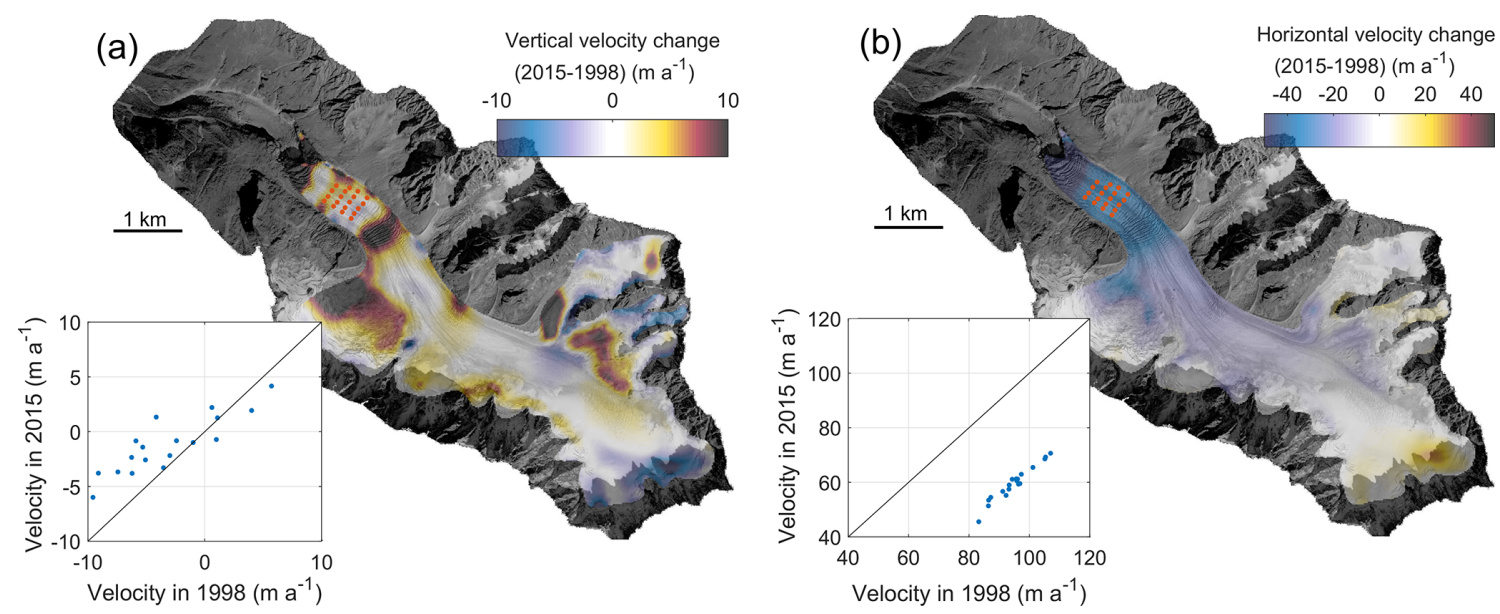

Figure 14. Modelled changes in vertical (a) and horizontal (b) surface velocities between 1998 and 2015. Insets compare modelled velocities at the stake location (orange dots) between 1998 and 2015.

tude that corresponds to the bottom tip of the GPS antenna. Except for the measurements performed at $2350 \mathrm{~m}$ a.s.l between 2016 and 2019, which were designed for this purpose, this gives an additional uncertainty of $\pm 0.1 \mathrm{~m}$ for the altitude of the bottom of the stake, i.e. $\pm 0.14 \mathrm{~m} \mathrm{a}^{-1}$ for the calculated vertical velocity.

The overall uncertainty in the geodetic point surface mass balance obtained from remote sensing data is therefore estimated to range between \pm 0.20 and $\pm 0.60 \mathrm{~m} \mathrm{a}^{-1}$ using accurate DEMs from UAV photogrammetry depending on the surface roughness and the method used for vertical velocity determination.

\section{Conclusions}

The classical way to determine the point surface mass balance in the ablation zone of a glacier is to set up ablation stakes and dig pits or conduct drillings in the accumulation zone. Here, we showed that, in the ablation zone, the point surface mass balances can be reconstructed from surface altitudes and horizontal velocities only, provided that the vertical velocities have been measured for at least 1 year in the past. Our method first requires accurate measurement of the vertical velocities between two years, $t$ and $t+1$, from stakes and GNSS measurements. Then, for the following or previous years, the point surface mass balances can be obtained easily from surface measurements only using the horizontal velocity and the surface elevation at each end of the horizontal displacement vector (Eq. 4). These measurements can be obtained from remote sensing provided that the ice flow velocity and altitude determinations are sufficiently accurate.

Our method assumes that the annual vertical velocities are almost constant with time. We have used a numerical modelling study to show that this approximation holds in areas of low bedrock slope (averaged over a distance greater than the 

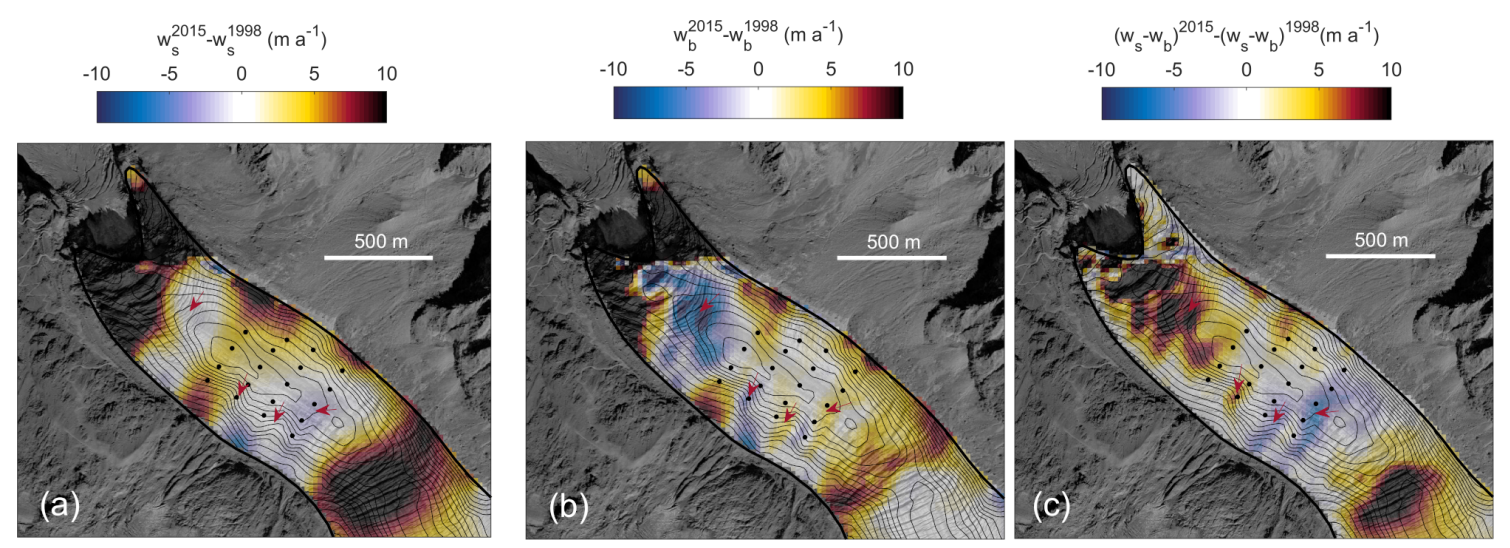

Figure 15. Modelled changes in vertical velocities at the surface (a) and at the bedrock (b) between 1998 and 2015 . The righthand figure (c) shows the change in vertical velocity at the surface due to changes in flow convergence/divergence. The red arrows indicate the locations where changes in basal vertical velocities are compensated for by flow convergence/divergence changes, resulting in constant surface vertical velocities.

ice thickness). This is supported by our detailed observations performed on the Argentière Glacier at $2400 \mathrm{~m}$ a.s.l. and designed for this purpose. A comparison between the reconstructed point surface mass balances and the observed values shows close agreement. Further tests performed on datasets acquired in other regions of the Argentière and Mer de Glace glaciers show standard deviations of \pm 0.2 to \pm 0.4 m w.e. $\mathrm{a}^{-1}$ between reconstructed and observed point surface mass balances despite the fact that these measurements were not designed for this purpose. For these tests, we used the averaged vertical velocities obtained over the last decade.

From our results, we conclude that the point surface mass balances can be obtained with an accuracy of about $0.3 \mathrm{~m}$ w.e. $\mathrm{a}^{-1}$ using remote sensing measurements and assuming that the vertical velocities have been observed accurately over the previous years within a radius of less than $15 \mathrm{~m}$. We also conclude from our datasets that the past period over which the vertical velocities are determined should not exceed 4 years in order to not exceed an uncertainty of $0.3 \mathrm{~m}$ w.e. $\mathrm{a}^{-1}$ on the reconstructed surface mass balance, although further observations and analysis are needed to better estimate these spatial and temporal changes. Note that, for comparison, the measurement uncertainty related to the in situ measurements of point surface mass balance is $0.14 \mathrm{~m}$ w.e. $\mathrm{a}^{-1}$ in the ablation zone (Thibert et al., 2008).

Given the recent improvements in satellite sensors, it is conceivable to apply our method using high-spatialresolution satellite images like Pléiades or WorldView $(0.5 \mathrm{~m}$ resolution). For these point surface mass balance reconstructions, note that, given the strong spatial variability in vertical velocity, it is crucial to determine the altitudes of the surface at each end of the horizontal displacement vector at the exact sites on which the vertical velocities are known. We conclude that our method could be useful to determine numerous point surface mass balances and reduce the amount of effort required to conduct field measurements, especially in remote areas.

Previous studies have shown that the point surface mass balance signal reveals a climatic signal that is unbiased by the dynamic glacier response, unlike the commonly used glacierwide mass balance (Rasmussen, 2004; Huss et al., 2009; Eckert et al., 2011; Thibert et al., 2018; Vincent et al., 2017). In the glaciological community, there is growing awareness that point surface mass balance measurements are important basic data to be shared for mass balance and climate change analyses. In this respect, the World Glacier Monitoring Service has started collecting such data on a systematic basis as a complement to glacier-wide surface mass balances (WGMS, 2020). Our method should open up new prospects to obtain more numerous point surface mass balances in the future while reducing the amount of time and energy required for in situ measurements.

Another line of research not explored in the present study could also be examined. The method proposed in the present study requires the vertical velocity to reconstruct the annual point surface mass balance. However, if we derive Eq. (4) and assume that vertical velocity is constant with time, we can determine the surface mass balance changes instead of the absolute surface mass balances with the elevation determinations only. Assuming that satellite sensors provide sufficient accuracy in elevation and horizontal velocity, this method could be very helpful to reconstruct changes in surface mass balance in remote areas for which in situ measurements are very difficult. In this way, point surface mass balance changes in numerous unobserved glaciers could be considered with remote sensing observations only. This would make it possible to obtain climatic signals all over the world which are unbiased by dynamic glacier response. 
Appendix A

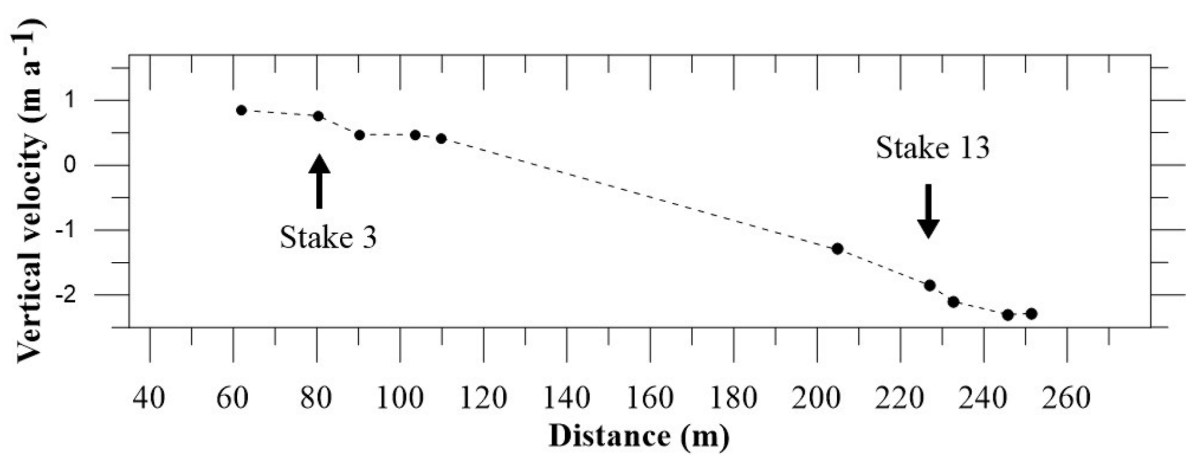

Figure A1. Vertical velocities obtained from 10 stakes measured in 2018/2019 on a longitudinal profile located between stakes 3 and 13 (see Fig. 2 for the locations of stakes 3 and 13). 
Data availability. The surface mass balance, ice flow velocities and DEM data can be accessed upon request by contacting Christian Vincent (christian.vincent@univ-grenoble-alpes.fr).

Author contributions. DC, OL, DS, BJ, LA, UN, AW, LP, OG, VP, ET, FB and CV performed the topographic measurements (photogrammetry, lidar, GNSS). OL, DC, AG, FG, OG, FB, AR, and $\mathrm{CV}$ performed the numerical calculations and the analysis. AG performed the numerical modelling calculations. CV supervised the study and wrote the paper. All co-authors contributed to the discussion of the results.

Competing interests. The authors declare that they have no conflict of interest.

Acknowledgements. This study was funded by the Observatoire des Sciences de l'Univers de Grenoble (OSUG) and the Institut des Sciences de l'Univers (INSU-CNRS) in the framework of the French GLACIOCLIM (Les GLACIers, un Observatoire du CLIMat) programme. IGE and ETGR are part of LabEx OSUG@2020 (Investissements d'avenir - ANR10 LABX56). We thank all those who conducted the field measurements. We are grateful to Harvey Harder for reviewing the English. We thank the editor, Kenichi Matsuoka, the reviewer, Ben Pelto, and an anonymous reviewer for their comments and suggestions that greatly improved the quality of the paper.

Financial support. This research has been supported by the Agence Nationale de la Recherche (grant no. ANR 18 CE1 0015 01) in the framework of the SAUSSURE programme (Sliding of glAciers and sUbglacial water preSSURE; https://saussure.osug.fr, last access: 25 February 2021).

Review statement. This paper was edited by Kenichi Matsuoka and reviewed by Ben Pelto and one anonymous referee.

\section{References}

Abermann, J., Kuhn, M., and Fischer, A.: Climatic controls of glacier distribution and glacier changes in Austria, Ann. Glaciol., 52, 83-90, https://doi.org/10.3189/172756411799096222, 2011.

Agisoft: Metashape Professional Edition, Version 1.5., Agisoft LLC, St. Petersburg, Russia, 2019.

Ayoub, F., Leprince, S., and Keene, L.: User's guide to COSICORR co-registration of optically sensed images and correlation, California Institute of Technology, Pasadena, CA, USA, 2009.

Azam, M. F., Wagnon, P., Berthier, E., Vincent, C., Fujita, F., and Kargel, J. S.: Review of the status and mass changes of Himalayan-Karakoram glaciers, J. Glaciol., 64, 61-74, https://doi.org/10.1017/jog.2017.86, 2018.

Bauder, A., Funk, M., and Huss, M.: Ice volume changes of selected glaciers in the Swiss Alps since the end of the 19th century, Ann. Glaciol., 46, 145-150, https://doi.org/10.3189/172756407782871701, 2007.

Berthier, E., Vadon, H., Baratoux, D., Arnaud, Y., Vincent, C., Feigl, K., and Rémy, F.: Surface motion of mountain glaciers derived from satellite optical imagery, Remote Sens. Environ., 95, 1428, https://doi.org/10.1016/j.rse.2004.11.005, 2005.

Berthier, E., Vincent, C., Magnússon, E., Gunnlaugsson, Á. P., Pitte, P., Le Meur, E., Masiokas, M., Ruiz, L., Pálsson, F., Belart, J. M. C., and Wagnon, P.: Glacier topography and elevation changes derived from Pléiades sub-meter stereo images, The Cryosphere, 8, 2275-2291, https://doi.org/10.5194/tc8-2275-2014, 2014.

Brun, F., Buri, P., Miles, E.S., Wagnon, P., Steiner, J., Berthier, E., Raglettli, S., Kraaijenbrink, P., Immerzeel, W., and Pellicciotti, F.: Quantifying volume loss from ice cliffs on debris-covered glaciers using high resolution terrestrial and aerial photogrammetry, J. Glaciol., 62, 684-695, https://doi.org/10.1017/jog2016.542016, 2016.

Brun, F., Berthier, E., Wagnon, P., Kääb, A., and Treichler, D.: A spatially resolved estimate of High Mountain Asia glacier mass balances from 2000 to 2016, Nat. Geosci., 10, 668-673, https://doi.org/10.1038/ngeo2999, 2017.

Cuffey, K., and Paterson, W. S. B.: The physics of glaciers, 4th Edition, Academic Press, Amsterdam, The Netherlands, 2010.

Dussaillant, I., Berthier, E., Brun, F., Masiokas, M., Hugonnet, R., Favier, V., Rabatel, A., Pitte, P., and Ruiz, L.: Two decades of glacier mass loss along the Andes, Nat. Geosci., 12, 802-808, https://doi.org/10.1038/s41561-019-0432-5, 2019.

Eckert, N., Baya, H., Thibert, E., and Vincent, C.: Extracting the temporal signal from a winter and summer mass-balance series: application to a six-decade record at Glacier de Sarennes, French Alps, J. Glaciol., 57, 134-150, https://doi.org/10.3189/002214311795306673, 2011.

Fischer, A.: Glaciers and climate change: Interpretation of 50 years of direct mass balance of Hintereisferner, Glob. Planet. Change, 71, 13-26, https://doi.org/10.1016/j.gloplacha.2009.11.014, 2010 .

Gagliardini, O., Zwinger, T., Gillet-Chaulet, F., Durand, G., Favier, L., de Fleurian, B., Greve, R., Malinen, M., Martín, C., Råback, P., Ruokolainen, J., Sacchettini, M., Schäfer, M., Seddik, H., and Thies, J.: Capabilities and performance of Elmer/Ice, a newgeneration ice sheet model, Geosci. Model Dev., 6, 1299-1318, https://doi.org/10.5194/gmd-6-1299-2013, 2013.

Gardelle, J., Berthier, E., and Arnaud, Y.: Slight mass gain of Karakoram glaciers in the early twenty-first century, Nat. Geosci., 5, 322-325, https://doi.org/10.1038/ngeo1450, 2012.

Gardner, A. S., Moholdt, G., Cogley, J. G., Wouters, B., Arendt, A. A., Wahr, J., Berthier, E., Pfeffer, T., Kaser, G., Hock, R., Ligtenberg, S. R. M., Bolch, T., Sharp, M., Hagen, J. O., van den Broeke, M. R., and Paul, P.: A reconciled estimate of glacier contributions to sea level rise: 2003-2009, Science, 340, 852857, https://doi.org/10.1126/science.1234532, 2013.

Gillet-Chaulet, F., Gagliardini, O., Seddik, H., Nodet, M., Durand, G., Ritz, C., Zwinger, T., Greve, R., and Vaughan, D. G.: Greenland ice sheet contribution to sea-level rise from a new-generation ice-sheet model, The Cryosphere, 6, 1561-1576, https://doi.org/10.5194/tc-6-1561-2012, 2012. 
Hantz, D. and Lliboutry, L.: Waterways, ice permeability at depth and water pressures at glacier d'Argentière, French Alps, J. Glaciol., 29, 227-238, 1983.

Hock, R., Jansson, P., and Braun, L.: Modelling the response of mountain glacier discharge to climate warming, in: Global Change and Mountain Regions - A State of Knowledge Overview, edited by: Huber, U. M., Reasoner, M. A., and Bugmann, H., Springer, Dordrecht, The Netherlands, 243-252, 2005.

Hoelzle, M., Azisov, E., Barandun, M., Huss, M., Farinotti, D., Gafurov, A., Hagg, W., Kenzhebaev, R., Kronenberg, M., Machguth, H., Merkushkin, A., Moldobekov, B., Petrov, M., Saks, T., Salzmann, N., Schöne, T., Tarasov, Y., Usubaliev, R., Vorogushyn, S., Yakovlev, A., and Zemp, M.: Reestablishing glacier monitoring in Kyrgyzstan and Uzbekistan, Central Asia, Geosci. Instrum. Method. Data Syst., 6, 397-418, https://doi.org/10.5194/gi-6-397-2017, 2017.

Huss, M.: Present and future contribution of glaciers to runoff from macroscale drainage basins in Europe, Wat. Resour. Res., 47, WO7511, https://doi.org/10.1029/2010WR010299, 2011.

Huss, M. and Bauder, A.: Twentieth-century climate change inferred from long-term point observations of seasonal mass balance, Ann. Glaciol., 50, 207-214, https://doi.org/10.3189/172756409787769645, 2009.

Huss, M. and Hock, R.: Global-scale hydrological response to future glacier mass loss, Nat. Clim. Change, 8, 135-140, https://doi.org/10.1038/s41558-017-0049-x, 2018.

Huss, M., Hock, R., Bauder, A., and Funk, M.: Conventional versus reference-surface mass balance, J. Glaciol., 58, 278-286, https://doi.org/10.3189/2012JoG11J216, 2012.

Immerzeel, W. W., Pellicciotti, F., and Bierkens, M. F. P.: Rising river flows throughout the twenty-first century in two Himalayan glacierized watersheds, Nat. Geosci., 6, 742-745, https://doi.org/10.1038/NGEO1896, 2013.

IPCC: IPCC Special Report on the Ocean and Cryosphere in a Changing Climate, edited by: Portner, H.-O., Roberts, D. C., Masson-Delmotte, V., Zhai, P., Tignor, M., Poloczanska, E., Mintenbeck, K., Alegriìa, A., Nicolai, M., Okem, A., Petzold, J., Rama, B., and Weyer, N. M., 755 pp., 2019.

Kääb, A. and Funk, M.: Modelling mass balance using photogrammetric and geophysical data: a pilot study at Griesgletscher, Swiss Alps, J. Glaciol., 45, 575-583, 1999.

Kaser, G., Cogley, J. G., Dyurgerov, M. B., Meier, M. F., and Ohmura, A.: Mass balance of glaciers and ice caps: Consensus estimates for 1961-2004, Geophys. Res. Lett., 33, L19501, https://doi.org/10.1029/2006GL027511, 2006.

Kaser, G., Grosshauser, M., and Marzeion, B.: Contribution potential of glaciers to water availability in different climate regimes, P. Natl. Acad. Sci. USA, 107, 20223-20227, 2010.

Kraaijenbrink, P. D. A., Immerzeel, W. W., Pellicciotti, F., de Jong, S. M., and Shea, J. M.: Object-based analysis of unmanned aerial vehicle imagery to map and characterise surface features on a debris-covered glacier, Remote Sens. Environ., 186, 581-595, https://doi.org/10.1016/j.rse.2016.09.013, 2016.

Leprince, S., Ayoub, F., and Avouac, J. P.: Automatic and precise orthorectification, coregistration, and subpixel correlation of satellite images, application to ground deformation measurement, IEEE T. Geosci. Remote, 45, 1529-1558, https://doi.org/10.1109/TGRS.2006.888937, 2007.
Marzeion, B., Cogley, J. G., Richter, K., and Parkes, D.: Attribution of global glacier mass loss to anthropogenic and natural causes, Science, 34, 919-921, https://doi.org/10.1126/science1254702, 2014.

Nienow, P. W., Hubbard, A. L., Hubbard, B. P., Chandler, D. M., Mair, D. W. F., Sharp, M. J., and Willis, I. C.: Hydrological controls on diurnal ice flow variability in valley glaciers, J. Geophys. Res., 110, F04002, https://doi.org/10.1029/2003JF000112, 2005.

Paul, F. and Haeberli, W.: Spatial variability of glacier elevation changes in the Swiss Alps obtained from two digital elevation models, Geophys. Res. Lett., 35, L21502, https://doi.org/10.1029/2008GL034718, 2008.

Rabatel, A., Sanchez, O., Vincent, C., and Six, D.: Estimation of glacier thickness from surface mass balance and ice flow velocities: a case study on Argentière glacier, France, Front. Earth Sci., 6, 112, https://doi.org/10.3389/feart.2018.00112, 2018.

Rasmussen, L. A.: Altitude variation of glacier mass balance in Scandinavia, Geophys. Res. Lett., 31, L13401, https://doi.org/10.1029/2004GL020273, 2004.

Soruco, A., Vincent, C., Francou, B., and Gonzalez, J. F.: Glacier decline between 1963 and 2006 in the Cordillera Real, Bolivia, Geophys. Res. Lett., 36, L03502, https://doi.org/10.1029/2008GL036238, 2009.

Sugiyama, S. and Gudmunsson, G. H.: Short-term variations in glacier flow controlled by subglacial water pressure at Lauteraargletscher, Bernese Alps, Switzerland, J. Glaciol., 50, 353-363, https://doi.org/10.3189/172756504781829846, 2004.

Thibert, E., Blanc, R., Vincent, C., and Eckert, N.: Glaciological and volumetric mass balance measurements: error analysis over 51 years for Glacier de Sarennes, French Alps, J. Glaciol., 54, 522-532, https://doi.org/10.3189/002214308785837093, 2008.

Thibert, E., Eckert, N., and Vincent, C.: Climatic drivers of seasonal glacier mass balances: an analysis of 6 decades at Glacier de Sarennes (French Alps), The Cryosphere, 7, 47-66, https://doi.org/10.5194/tc-7-47-2013, 2013.

Thibert, E., Sielenou, P., Vionnet, V., Eckert, N., and Vincent, C.: Causes of glacier melt extremes in the Alps since 1949, Geophys. Res. Lett., 45, 817-825, https://doi.org/10.1002/2017GL076333, 2018.

Vincent, C.: Influence of climate change over the 20th Century on four French glacier mass balances, J. Geophys. Res., 107, 1-12, https://doi.org/10.1029/2001JD000832, 2002.

Vincent, C., Kappenberger, G., Valla, F., Bauder, A., Funk, M., and Le Meur, E.: Ice ablation as evidence of climate change in the Alps over the 20th century, J. Geophys. Res., 109, D10104, https://doi.org/10.1029/2003JD003857, 2004.

Vincent, C., Soruco, A., Six, D., and Le Meur, E.: Glacier thickening and decay analysis from fifty years of glaciological observations performed on Argentière glacier, Mont-Blanc area, France, Ann. Glaciol., 50, 73-79, https://doi.org/10.3189/172756409787769500, 2009.

Vincent, C., Fischer, A., Mayer, C., Bauder, A., Galos, S. P., Funk, M., Thibert, E., Six, D., Braun, L., and Huss, M.: Common climatic signal from glaciers in the European Alps over the last 50 years, Geophy. Res. Lett., 44, 1376-1383, https://doi.org/10.1002/2016GL072094, 2017.

Vincent, C., Dumont, M., Six, D., Brun, F., Picard, G., and Arnaud, L.: Why do the dark and light ogives of Forbes bands 
have similar surface mass balances?, J. Glaciol, 64, 236-246, https://doi.org/10.1017/jog.2018.12, 2018a.

Vincent, C., Soruco, A., Azam, M. F., Basantes-Serrano, R., Jackson, M., Kjøllmoen, B., Thibert, E., Wagnon, P., Six, D., Rabatel, A., Ramanathan, A., Berthier, E., Cusicanqui, D., Vincent, P., and Mandal, A.: A nonlinear statistical model for extracting a climatic signal from glacier mass balance measurements, J. Geophys. Res.-Ea. Surf., 123, 2228-2242, https://doi.org/10.1029/2018JF004702, 2018b.

Wagnon, P., Vincent, C., Arnaud, Y., Berthier, E., Vuillermoz, E., Gruber, S., Ménégoz, M., Gilbert, A., Dumont, M., Shea, J. M., Stumm, D., and Pokhrel, B. K.: Seasonal and annual mass balances of Mera and Pokalde glaciers (Nepal Himalaya) since 2007, The Cryosphere, 7, 1769-1786, https://doi.org/10.5194/tc7-1769-2013, 2013.
World Glacier Monitoring Service (WGMS): Global Glacier Change Bulletin No. 3 (2016-2017), edited by: Zemp, M., Gärtner-Roer, I., Nussbaumer, S. U., Bannwart, J., Rastner, P., Paul, F., and Hoelzle, M., ISC(WDS)/IUGG(IACS)/UNEP/UNESCO/WMO, World Glacier Monitoring Service, Zurich, Switzerland, 274 pp., publication based on database version: https://doi.org/10.5904/wgmsfog-2019-12, 2020.

Zemp, M., Huss, M., Thibert, E., Eckert, N., McNabb, R., Huber, J., Barandun, M., Machguth, H., Nussbaumer, S. U., GärtnerRoer, I., Thomson, L., Paul, F., Maussion, F., Kutuzov, S., and Cogley, J. G.: Global glacier mass changes and their contributions to sea-level rise from 1961 to 2016, Nature, 568, 382-386, https://doi.org/10.1038/s41586-019-1071-0, 2019. 